\title{
Dynamical seasonal climate prediction using an ocean-atmosphere coupled climate model developed in partnership between South Africa and the IRI
}

\author{
Asmerom F. Beraki ${ }^{1}$ \\ South African Weather Service, Pretoria, South Africa and \\ Department of Geography, Geoinformatics and Meteorology, \\ University of Pretoria, South Africa
}

David G. DeWitt

International Research Institute for Climate and Society, Columbia University, Palisades, New York

Current affiliation NOAA/NWS

Willem A. Landman

Council for Scientific and Industrial Research, Natural Resources and the Environment, Pretoria, South Africa

Department of Geography, Geoinformatics and Meteorology,

University of Pretoria, South Africa

Cobus Olivier

South African Weather Service, Pretoria, South Africa and Department of Geography, Geoinformatics and Meteorology,

University of Pretoria, South Africa

${ }^{1}$ Corresponding author address: Asmerom F. Beraki, South African Weather Service, Private Bag X097, Pretoria, 0001, South Africa.

E-mail: asmerom.beraki@weathersa.co.za 


\section{Abstract}

The resent increase in availability of high-performance computing (HPC) resources in South Africa allowed the development of an Ocean-Atmosphere coupled general circulation model (OAGCM). The ECHAM4.5-MOM3-SA is the first OAGCM to be developed in Africa for seasonal climate prediction. This model employs an initialization strategy that is different from previous versions of the model that coupled the same atmosphere and ocean models. Evaluation of hindcasts performed with the model revealed that the OAGCM is successful in capturing the development and maturity of ElNiño and La-Niña episodes up to 8 months ahead. A model intercomparison also indicated that the ECHAM4.5-MOM3-SA has skill levels for the Niño-3.4 region SST comparable with other coupled models administered by international centres. Further analysis of the coupled model revealed that La-Niña events are more skillfully discriminated than El-Niño events. However, as is typical for OAGCM the model skill was generally found to decay faster during the spring barrier.

The analysis also showed that the coupled model has useful skill up to several months lead-time when predicting the equatorial Indian Ocean Dipole (IOD) during the period spanning between the mid austral spring and the start of the summer seasons which reaches its peak in November. The weakness of the model in other seasons was mainly caused by the western segment of the dipole which eventually contaminates the Dipole Mode Index (DMI). The model is also able to forecast the anomalous upper air circulations, particularly in the equatorial belt, and surface air temperature in the southern African region as opposed to precipitation. 


\section{Introduction}

The most physically realistic and computationally expensive method of modelling the climate system is to model all components of the system believed to be relevant at the timescales of interest. At the seasonal lead-time for instance, the minimum level of complexity required is a model which coupled the atmosphere and the ocean (e.g., Stockdale et al. 1998; Palmer et al. 2004; DeWitt 2005; Graham et al. 2005; Guérémy et al. 2005; Saha et al. 2006).

The South African modelling community has over the past decade or so dedicated a large amount of resources to utilize Atmospheric General Circulation Models (AGCMs) as operational seasonal forecast tools (Landman et al. 2012). These models have all been developed outside of South Africa, but have been used extensively for operational seasonal forecast production as well as for research by many institutions including, inter alia, the South African Weather Service (COLA T30 - Kirtman et al. 1997; ECHAM4.5 - Roeckner et al. 1996), the Universities of Cape Town (HadAM3P Pope et al. 2000) and the Council for Scientific and Industrial Research (CCAM McGregor 1996). Due to the enormous computational resources required to develop and run an operational forecast system based on coupled models, their engagement for realtime forecasts in South Africa has not previously been tractable. In fact, only a few institutions which are designated as global producing centres by the World Meteorological Organization (WMO) for long-range forecasts using coupled models for operational seasonal forecasting (Stockdale et al. 2009).

More recently, however, the ECHAM4.5 AGCM (Roeckner et al. 1996) has been coupled with the Geophysical Fluid Dynamics Laboratory (GFDL) Modular Oceanic 
Model version 3 (MOM3; Pacanowski and Griffes 1998) at the South African Weather Service (SAWS) hereafter referred to as the "ECHAM4.5-MOM3-SA" OceanAtmosphere coupled General Circulation Model (OAGCM). In addition, this coupled model employs an initialization strategy that capitalizes on best available information (Balmaseda and Anderson 2009). The use of real-time atmospheric states for initialization becomes possible with an atmospheric initial condition interface introduced in the model configuration. This interface is based on the vertical interpolation scheme originally suggested by Majewski (1985) that employs the integration of the hydrostatic equation but with numerical adjustment (I. Kirchner 2001, unpublished manuscript) coded in a software package referred to as INTERA (INTerpolation of ECMWF ReAnalysis data) ${ }^{2}$. We used this software to develop the interface that makes the OAGCM's configuration uniquely different from previous systems involving the ECHAM4.5 AGCM coupled with the MOM3 OGCM (e.g., DeWitt 2005; hereafter referred to as "D05"). Our motivation for this work is twofold. First, it has been demonstrated that southern African midsummer rainfall variability has been shown to be sufficiently predictable by using the coupled model outputs such as from DEMETER (Development of a European Multimodel Ensemble system for seasonal to inTERannual prediction) project (Palmer et al. 2004) and the IRI, especially during El Niño and La Niña seasons (Landman et al. 2012; Landman and Beraki 2012). As noted above, coupled models are largely assumed or hypothesized to represent the state of the art of seasonal forecasting. In fact, it has been conclusively shown through the DEMETER project that coupled forecasting systems can predict both the evolution of SSTs and atmospheric conditions at enhanced levels of skill. This fact, indeed, stimulates the need to use

${ }^{2}$ Available: http://wekuw.met.fu-berlin.de/ IngoKirchner/nudging/nudging/software/index.html 
coupled models in South Africa and renders them ideal candidates for seasonal climate prediction.

Second, with the inception of the Centre for High Performance for Computing (CHPC), the computational resources in South Africa has grown exponentially, consequently creating an environment for computationally intensive modelling research locally which would have been impossible otherwise. This recent advances in computing infrastructures compounded with the support from international institutions such as the International Research Institute for Climate and Society (IRI) in developing the coupled model described have paved the way for utilising and for further development of such state-of-the-art coupled models for seasonal forecast production and research. The aim of this paper is therefore to describe and evaluate the ECHAM4.5-MOM3-SA OceanAtmosphere Coupled Model (OAGCM) developed in partnership between South Africa and IRI.

The remainder of the paper is organized as follows. In sections 2 we describe the coupled model. The methodology of generating the hindcasts along with the initialization strategy is explained in section 3. In section 4 we evaluate the performance of the coupled model as a seasonal forecasting tool. A summary and conclusions are given in section 5 .

\section{Coupled model description}

The ECHAM4.5 AGCM (Roeckner et al. 1996) is coupled with the GFDL MOM3 (Pacanowski and Griffes 1998) using the Multiple Program and Multiple Data (MPMD) fully parallelized coupler paradigm (Komori et al. 2010). Essentially, this means that the atmosphere and ocean models are the same as standalone versions except for changes 
needed to handle the passing of data in between. Each model is treated as an independent set of Message Passing Interface (MPI) parallel processes. In contrast, D05 employed the Ocean Atmosphere Sea Ice Soil (OASIS) coupling software (Terray et al. 1999) produced by the European Centre for Research and Advanced Training in Scientific Computation (CERFACS)" to couple the models despite that the principle on which the exchange of information between the AGCM and OGCM remains similar. The atmosphere and ocean models along with the coupling scheme are described next.

\section{a. Atmospheric model}

The AGCM is originally evolved from the spectral weather forecast model of the European Centre for Medium Range Weather Forecasts (ECMWF; Simmons et al. 1989). Numerous modifications (in dynamics and physics) have been applied to this model at the Max Planck Institute for Meteorology (MPI) to make it suitable for climate predictions and it is the fourth generation in a series. This has been shown to have promising seasonal predictive capability for the southern Africa region (Landman et al. 2009).

The prognostic variables are represented by truncated series of spherical harmonics with triangular truncation at wave number 42 (T42) except for the moisture and trace substances. Vertically 19 unevenly spaced hybrid sigma layers are used. The model employs the vertical coordinate system of Simmons and Burridge (1981) and a semi-Lagrangian transport scheme of Williamson and Rasch, (1994) for water vapour, cloud water and trace substances. It uses the Longwave radiation of Fouquart and Bonnel (1980) and shortwave radiation of Morcrette et al. (1986). Cumulus convection is parameterized using the mass flux scheme of Tiedtke (1989) but incorporates the modifications introduced by Nordeng (1994). The turbulent surface fluxes are calculated 
from Monin-Obukhov similarity theory (Louis 1979), but different from its predecessors, a higher-order closure scheme (Brinkop and Roeckner 1995) is used to simulate the vertical diffusion of heat, momentum, moisture and cloud water. Horizontal diffusion is computed using the Laursen and Eliasen (1989) scheme. The orographic gravity waves are represented by the wave drag parameterization due to Miller et al. (1989). We refer the reader to Roeckner et al. (1996) for a complete model description.

\section{b. Ocean model}

The Ocean model MOM3 is a finite-difference treatment of the primitive equations of motion using the Boussinesq and hydrostatic approximations in spherical coordinates. Spatially it covers the global ocean ranges between $74^{\circ}$ South and $65^{\circ}$ North. The coastline and bottom topography are realistic but the minimum and maximum ocean depths are assumed 100 and $6000 \mathrm{~m}$ respectively. The artificial high-latitude meridional boundaries are impermeable and insulating. The model has a $0.5^{\circ}$ uniform zonal resolution, variable meridional resolution with a $0.5^{\circ}$ between $30^{\circ} \mathrm{S}$ and $10^{\circ} \mathrm{N}$, gradually increasing to $1.5^{\circ}$ at $30^{\circ} \mathrm{N}$ and fixed at $1.5^{\circ}$ in the extratropics. There are 25 layers in the vertical with 17 layers in the upper levels between $7.5 \mathrm{~m}$ and $450 \mathrm{~m}$. The vertical mixing scheme is the nonlocal K-profile parameterization (KPP) scheme of Large et al. (1994). The horizontal mixing of tracers and momentum is Laplacian. The momentum mixing uses the space-time-dependent scheme of Smagorinsky (1963) and the tracer mixing uses Redi (1982) diffusion along with Gent and McWilliams (1990) quasi-adiabatic stirring.

\section{c. Coupling procedure}


The two GCMs exchange information once per simulation day. The AGCM feeds the OGCM with heat, momentum, freshwater, and surface solar flux. The OGCM, in turn, feeds the AGCM sea-surface temperature (SST) information. The coupling strategy used in this configuration is anomaly coupling on the AGCM side and full-field coupling on the OGCM side meaning that the anomalous atmospheric fluxes are super-imposed on the observed climatology. This procedure is the same as followed by Ji et al. (1998). The climatological AGCM fluxes are computed using a long-term climatology obtained from the uncoupled AGCM forced with observed SST. The climatological AGCM fluxes are subtracted from the fluxes computed by the AGCM component model in the coupled model to form anomalies. In addition, since the ocean model lacks a sea-ice model, the OGCM SST is relaxed toward the observed climatology in high latitudes to suppress the generation of spurious ice.

\section{Retroactive forecasts design}

The OAGCM uses initial states of the atmosphere, land surface and ocean. While the use of the ocean and land surface states is straightforward, the atmospheric state needs cautious treatment prior to initializing the coupled model. In this process, the model is initialized with the National Centers for Environmental Prediction (NCEP) daily atmospheric initial states, interpolated into the AGCM's vertical and horizontal resolution in a manner that respects numerical stability as explained above. The atmospheric initial conditions in D05, however, were taken from simulations made with the (ECHAM4.5) AGCM forced by the temperature from the uppermost layer of the ODA product, which is equivalent to the (MOM3) OGCM SST. Despite that the atmospheric initial conditions become less important as the lead-time increases (Goddard et al. 2001), it is worth 
emphasizing that the fast development of both computational technology and observational network (particularly with the advent of meteorological satellite information) has an immense contribution on the improvement in forecast quality. Theoretically, improving the predictability of the mean state of the atmosphere, to a large extent, is expected to arise from the improvement of, apart from dynamical and physical processes, optimal estimate of the state of the climate system (Balmaseda and Anderson 2009; Doblas-Reyes et al. 2013). The use of realistic atmospheric and land surface (soil moisture) states in the ECHAM4.5-MOM3-SA configuration is, therefore, viewed from this perspective. The contribution of this initialization strategy to the overall forecast quality improvement is underway using different simulations of the ECHAM4.5 AGCM only.

The OAGCM is initialized using slightly different atmospheric initial states to build an ensemble prediction system. The technique is however applied only to the atmospheric state (section 3a) meaning that the OAGCM is constrained with a fixed ocean state for all ensemble members which fall within the proximity of the forecast date (in our case the $4^{\text {th }}$ of each month). The uncertainties which arise from the initial conditions are accounted for by taking 10 consecutive daily atmospheric states back from the forecast date in each month and year. For the November hindcasts for example the atmospheric initial conditions cover the period from October 26 to November 4 for 28 years starting from 1982 to 2009 . This approach is slightly different from the Climate Forecasting System (CFS) of NCEP (Saha et al. 2006) which considers pentad initial conditions. Each retrospective forecast is of 9 months length. The procedures of generating the various initial states are described below. 


\section{a. Atmospheric initial states}

The atmospheric initial conditions are obtained from the National Centers for Environmental Prediction, Department of Energy (NCEP/DOE) Atmospheric Model Intercomparison Project (AMIP) II Reanalysis (R2) dataset (Kanamitsu et al. 2002) except that the lower layer atmospheric temperature is assimilated from the upper layer of the GFDL ocean data assimilation (ODA) system in order to minimize the imbalance between the (near-equatorial) upper-ocean mass field and wind stress (D05). The NCEP/DOE atmospheric states are transformed to the horizontal and vertical resolution (T42L19) of the ECHAM4.5 AGCM as noted in section 2(a). In general, the process involves: 1) conversion of pressure to a hybrid-sigma coordinate system (Simmons and Burridge, 1981), 2) computation of vorticity and divergence from meridional and zonal wind components and 3) transformation of grid to spectral space. The latter component is applied on prognostic variables, i.e., temperature, vorticity and divergence only as the specific humidity needs to remain in the corresponding Gaussian grid resolution.

The vertical coordinate system transformation requires careful treatment to ensure that an initial state is produced that is numerically and gravitationally stable. The ECHAM4.5 AGCM was found to be sensitive to be numerically unstable when a linear or non-linear interpolation scheme without adjustment was employed. The difficulties associated with the vertical interpolation were noted in various previous studies (e.g. Majewski 1985; Shen et al. 1986; Gaertner and Castro 1996). The horizontal truncation may also potentially introduce imbalances presumably due to normal mode variations between the NCEP/DOE and the model. To minimize the problem, the vertical interpolation was conducted in a manner that preserves the structure of the vertical 
stratification of the atmosphere. The scheme is based on the vertical integration of the hydrostatic equation with adjustment (I. Kirchner 2001, unpublished manuscript). The interpolation scheme is originally suggested by Majewski (1985) and is also widely used for conversion between models fields of different resolution in the HIRLAM (High Resolution Limited Area Model; Undén et al. 2002) community.

\section{b. Preparation of land surface state}

The AGCM land surface model is initialized with observed soil moisture states. The soil moisture is taken from the Climate Prediction Center (CPC) monthly mean dataset (Fan and van den Dool 2004). The CPC product is interpolated to the AGCM resolution using a bi-linear interpolation procedure. The AGCM uses the simple biosphere model (Sellers et al. 1986) and soil hydrology parameterization scheme suggested by Dümenil and Todini (1992). Many studies highlighted the role of soil moisture initialization on the skill of climate models (e.g., Walker and Rowntree 1977; Koster et al. 2004; Conil et al. 2009; Douville 2010). However, it is beyond the scope of this work to assess the sensitivity of the OAGCM to soil moisture initialization alone. The goal is rather to optimize the forecasting system for predictive skill in an operational context.

\section{c. Preparation of ocean state}

The ocean initial conditions are taken from ODA system produced at the GFDL that employs an optimum interpolation scheme (Derber and Rosati 1989). The ODA uses expendable bathythermograph (XBT) data for the subsurface and relaxes the SST to observed values with a 5-day time scale. The use of the product is done by the horizontal 
and vertical interpolation procedure described by D05. The procedure reportedly leads to a reasonable balanced ocean initial state for use in making SST forecasts.

\section{Performance statistics}

The OAGCM's deterministic and probabilistic skill of the models respective has been explored for different months and seasons along with several lead-times.

The verification is based on 3360 (12 months x 28yrs x 10 ensemble members) hindcasts each consisting of 9-month integrations. The model runs are grouped according to the forecast date (if they were issued) to a set of hindcasts with 10 ensemble members. Each ensemble set mimics a set of operational forecasts issued on the $4^{\text {th }}$ of each month starting from 1982 to 2009 . The model bias in the mean annual cycle was removed from the model forecasts prior to comparing the statistics, that is, computing the anomalies of the model about its own drifted climatology as a function of different initialization time and lead-months (Wang et al. 2002; Schneider et al. 2003; D05).

The model surface and upper air data were compared against observed data compiled from different sources. For the surface variables, rainfall and air temperatures, the observed data sets used for comparison were the CPC Merged Analysis of Precipitation (CMAP; Xie and Arkin 1997) and Climate Research Unit (CRU; New et al. 2000). The SST forecasts were compared against optimum interpolation SST (OISST) version 2 (Reynolds et al. 2002). For the upper air analysis, the NCEP/DOE R2 (Kanamitsu et al. 2002) was used as a proxy for observation.

a. Deterministic forecast verification 
Although operational seasonal forecasts are commonly issued probabilistically, it is also often informative to investigate their deterministic forecast performance. It is worth noting first that no cross-validation is conducted on the OAGCM SST hindcasts meaning that all the verification scores are computed directly from hindcasts as in D05. The most commonly used measures of skill in predicting the SST of the Equatorial Pacific Ocean are anomaly correlation (AC) and root-mean-square error (RMSE). Fig.1 shows the AC of the Nino3.4 basin $\left(5^{\circ} \mathrm{S}-5^{\circ} \mathrm{N}, 170^{\circ}-120^{\circ} \mathrm{W}\right)$ for 12 initial condition (IC) months and 9 months lead-time integrations. The model is successful in predicting the Nino3.4 SSTs well ahead of time and in most instances the ACs exceed 0.6 up to an 8 month lead-time for the ICs considered here. An AC 0.5 to 0.6 is commonly used as an indicator for the skilful forecast of the equatorial Pacific SST in the forecasting literature (e.g., Kirtman 2003; Schneider et al. 2003; D05). The ECHAM4.5-MOM3-SA struggles to maintain the defined skill threshold at higher lead-times (> 6 month lead-time) for May, June and July target months. This result is consistent with the CFS of NCEP (Saha et al. 2006). This sudden decay in skill near April is commonly referred to as the spring barrier in the literature and as Saha et al. (2006) suggested the spring barrier renders the austral winter months, most notably July forecasts to be more difficult.

The overall accuracy of model SST forecasts for the Nino3.4 region is also assessed using the RMSE. Our model has very low error concentrations for nearly all IC cases considered here, but with errors increasing as a function of lead-time (Fig. 2). The model error is confined within the range of 0.1 and $0.5^{\circ} \mathrm{C}$. At increased lead-times (at about 5 or more months lead-times), such as for October, November, December and January ICs, the model has relatively large biases. 
The time evolution of observed vs. model simulated the El Niño-Southern Oscillation (ENSO) phenomenon is shown in Fig. 3.The SST indices are area average anomalies for the Nino3.4 region similar to the index used for the computation of the AC (Fig. 1) or RMSE (Fig. 2) but for seasons instead of months. According to Fig. 3 the model agrees very well with observation for different lead-times for the austral summer (December to February; DJF) and austral fall (September to November; SON). The other seasons are relatively less skilful and uncertain specifically during the austral winter (June to August; JJA) as expected due to the spring barrier noted earlier. The skill enhancement shown in Fig. 1, to the large extent, is the contribution of the model's ability to capture the amplitude of the El Niño phases (Fig. 3) accurately except during the early 1990s. However, the model seems to overestimate the annual amplitude or interannual variability of La Niña phases. This tendency is, however, not as striking when assessing the probabilistic skill of the model when the skill is decomposed in to various categories (see section 3(b)).

The global skill distribution of the ECHAM4.5-MOM3-SA for the start of the austral summer (December) at 0 to 5 months lead-time is shown in Fig. 4. The central and eastern equatorial Pacific region remains the area of highest predictability and is associated with coherent spatial skills statistically significant at the 95\% level except at zero month lead-time (Fig. 4a) when a similar skill is also found in other ocean basins. During austral winter, the model forecast skill is similar during austral summer except that the highest skill area is also expanded towards the western part of the equatorial Pacific region. The magnitude of the skill is, however, relatively weakened toward the 
west as a function of lead-time (Fig. 5). The austral autumn and spring seasons (not shown) reveal a great deal of similarities with the austral summer and winter respectively. Model intercomparison is also a useful tool and commonly practiced in the area of model evaluation (e.g., Landman and Mason 2001; Schneider et al. 2003; Alves et al. 2004; D05; Saha et al. 2006). The SST prediction for the Nino3.4 area is usually used as a benchmarking for this type of comparison since ENSO is the most predictable component of the climate system (Fig. 9). For this purpose, we used the DEMETER models (Palmer et al. 2004), the CFS coupled model (Saha et al. 2006), D05 and a statistical model (MMS; Beraki et al. 2012) to investigate whether our model has a reasonable skill level compared to other similar models. The data for the DEMETER models are only available for 1981-2001 whereas the other models hindcasts presented here are from 1982 to 2009 . These differences may pose some difficulties in making objective or fair judgement. For this reason, we restrict the hindcast period to 1982-2001 for this model intercomparison purpose. In addition, no interpolation was performed on the individual models rather the observed SST is interpolated to each model's resolution to minimize the noise that might be introduced as a result. The DEMETER OAGCMs considered in this comparison comprise of the UKMO (United Kingdom Met Office; Pope et al. 2000), MF (Météo-France; Déqué 2001) and ECMWF (European Centres for Medium-Range Weather Forecast; Gregory et al. 2001).

The skill and accuracy of the different models computed from their hindcasts initialized in November and February are illustrated in Figs. 6 and 7, respectively. The choice of the November and February ICs were dictated by the availability of the DEMETER models' hindcast data. In the November IC, our coupled model demonstrates 
a competitive skill with most of the models considered here. The ECHAM4.5-MOM3-SA (denoted as SCM) maintains its AC at or above 0.8 across all lead-times; the skill for ECMWF, CFS and MMS starts decaying faster at lead-time 5 (Fig. 6a). In the February IC (Fig. 6b), all models tend to show similar tendency at all lead-times to that of the November IC. The exception is that the skill level in February initialized runs is generally low. The ECMWF, CFS and MMS decay faster relative to the other models at longer lead-times.

It is imperative to accompany the $\mathrm{AC}$ with a measure of accuracy or bias because the $\mathrm{AC}$ is not sensitive to bias since a biased forecasting system can still produce good AC. The RMSE computed for each model forecast set against the OI-SST is shown in Fig. 7. In the November IC (Fig. 7a), the ECHAM4.5-MOM3-SA achieves a comparable level of accuracy relative to the DEMETER models where MF is found to have the highest skill. The MMS (specifically at the start) and CFS (as the lead-time increases) show a gradual growth in error. In the February IC case (Fig. 7b), errors grow the fastest with increasing lead-time for the ECHAM4.5-MOM3-SA (1 to 3 months lead).

The MMS shows a tendency of greater error growth in the context of ENSO forecasts at the start of the austral summer even though it demonstrates a robust performance in the February initialized ENSO forecasts. ECHAM4.5-MOM3-SA performance is nearly comparable with the OAGCMs which are performing best in the cases we considered except for the relative error growth noted earlier.

The skill of the ECHAM4.5-MOM3-SA OAGCM in predicting ENSO during the austral summer is an improvement over D05 for the first four lead-months (0 to 3; Figs. 6a and 7a) and then tends to decay faster after that. In addition, our coupled model 
simulated the amplitude of ENSO more realistically than D05 (Fig. 9) when the amplitude of the seasonal variation of ENSO peaks (Fig. 8). Notwithstanding, in the February initialized hindcasts (Figs. 6b and 7b), D05 did well compared to our model. The result suggested that the impact of the initialization strategy apparently becomes noticeable when ENSO becomes active (Fig. 8). Generally, the two models, however, demonstrated comparable skill levels particularly in the context of rainfall and Indian Ocean Dipole (IOD) forecasts.

Previous studies highlighted the role of the coupling of the equatorial Indian Ocean basin with southern African rainfall variability (e.g., Reason 1999, 2002; Reason and Mulenga 1999; Washington and Preston 2006). It was hypothesized that this coupling phenomenon is found to drive the southern African extratropical climate system through the influence of large-scale rainfall bearing systems such as the relative annual position of the Inter-Tropical Convergence Zone (ITCZ), the South Atlantic anticyclone, and the midlatitude westerlies (Reason, et al. 2006). However, the SST prediction over the equatorial Indian Ocean has been found to be more complex and challenging. In fact, state-of-the-art coupled climate models are most often unable to replicate the observed evolving SST patterns over this ocean region (Collins et al. 2004; Landman et al. 2009). It is therefore not surprising that our model also had difficulty in simulating the observed SST patterns over the equatorial Indian Ocean sub-domain. The model shows some skill in simulating the SSTs over the western equatorial Indian Ocean off the coast of the African sub-continent except during austral autumn. However, the model manages to capture the eastern part of the equatorial Indian Ocean SST patterns near the coast of north-western Australia starting from the mid austral spring toward the beginning of the 
austral summer season. To substantiate this notion, we conducted model intercomparison to investigate the models' ability to simulate the equatorial Indian Ocean Dipole (IOD) using the Dipole Mode Index (DMI; Saji et al. 1999). The DMI is the SST anomaly difference between western $\left(50^{\circ} \mathrm{E}-70^{\circ} \mathrm{E}, 10^{\circ} \mathrm{S}-10^{\circ} \mathrm{N}\right)$ and eastern $\left(90^{\circ} \mathrm{E}-110^{\circ} \mathrm{E}, 10^{\circ} \mathrm{S}-\mathrm{Eq}\right)$ tropical Indian Ocean and commonly used to measure the strength and phases of the IOD (Saji et al. 1999). The model intercomparison analysis conducted during active period of IOD and ENSO (Fig., 8; Zhao and Hendon 2009) suggested that all the coupled models considered demonstrated marginal skill relative to ENSO despite that IOD is more predictable than rainfall (Fig. 9). Most of the coupled models overestimated or underestimated the amplitude of the IOD except for the MF coupled model. Notwithstanding, all models showed comparable level of skill, in the range of 0.8 and 0.9 $\mathrm{AC}$, in predicting IOD for austral spring (September to November; SON) at 0-month lead.

The seasonal variation of the IOD fully develops during the austral spring (SON; Fig. 8; Saji et al. 1999; Zhao and Hendon 2009). The model generally underestimated the amplitude of the seasonal variation of IOD particularly for the first few lead-months as opposed to the model's tendency to overestimate the amplitude of the seasonal variation of ENSO. Notwithstanding, the best performance of the model closely followed the observed peak of the seasonal cycle of the standard deviation of the IOD. Fig. 10 shows the predicted time evolution of the IOD during SON and OND (October to December) at different lead-times (1-4 months) over the verification period of 1982-2009 using a boxwhisker representation. The model was found to be skilful during the SON and OND seasons. For most cases the observations (green asterisks) are dressed with the ensemble 
spread and tend to cluster within the same categories as delineated by the historical $25 \%$ and $75 \%$ percentiles of both the observation (green line) and ensemble mean (blue line). However, there are cases where observations lie outside the ensemble spread specifically during the1990s. These outliers might be significantly contributed to the model's tendency to damp the amplitude of seasonal variation of the IOD (Fig. 8). This suggests that there is still room for further improvement by simply increasing the ensemble size of the OAGCM integrations. In addition, the model performance during the same period but for individual months measured using the AC and RMSE is also shown in Table 1. The model demonstrates good skill (statistically significant at 5\% confidence level) up to 5 months lead-time which attains its peak during November. Nonetheless, the model tends to show the smallest error growth during December presumably due to the subsidence of the IOD maturity or variation.

We also extended our analysis on the upper air fields of the model using the mean square skill score (MSSS; Murphy 1988). This score can easily be computed using the Mean Absolute Error (MAE) or Mean Square Error (MSE) where the latter is employed here. Usually the reference (control) forecasts are provided either by the climatology or persistence of the variable of interest (Wilks 2006). The skill score therefore represents improvements in the forecast skill relative to the reference. The MSSS has a value of one for perfect forecasts. The MSSS could be positive (negative) when the accuracy of the forecast is superior (inferior) to the accuracy of the reference forecast. When the MSE of the reference and forecast are equal, the MSSS becomes zero which implies no improvement in the forecast system relative to the reference forecast. The spatial distribution of global actual-skills (MSSS) of the OAGCM during the austral summer for 
geopotential height $(\mathrm{GH})$ is shown in Fig. 11. The skill score is computed from the ensemble mean of the model against the NCEP/DOE. On a synoptic scale, it is evident that the model, initialized in November, performs well at simulating the 850 and $500 \mathrm{hPa}$ GH over the equatorial region, specifically over the latter. Of particular interest is that the OAGCM outscores the forecast of climatology further south, particularly on those key ocean basins which are recognized modes of atmospheric variability such as the South Pacific Wave (SPW) train (Mo and Ghil 1987) and the Southern Annular Mode (SAM).

The OAGCM's performance in predicting wind components was also evaluated based on the ensemble mean integrations. Fig. 12 shows the equatorial zonal and meridional wind anomaly $\left(20^{\circ} \mathrm{S}\right.$ to $\left.20^{\circ} \mathrm{N}\right)$ skill during the austral summer (DJF) at various forecast lead-times (seasons) as a function of pressure levels computed against the NCEP/DOE. The result suggested that the model showed some skill on the lower tropospheric and upper stratospheric tropical flow as opposed to the extratropical flow. The analysis further revealed that the zonal wind appears to be more predicable than the meridional flow which might be attributed to ENSO forcing. Saha et al. (2006) demonstrated similar skill on the stratospheric zonal flow based on the CFS coupled model. Our coupled model is, however, struggling to predict the upper air flow between the upper troposphere and lower stratosphere. Mathole et al. (2013) recently identified similar deficiency in the ECHAM4.5-MOM3-SA OAGCM. They indicated that the OAGCM was unable to simulate the observed pole ward migration of the eddy driven southern extratropical jet stream and lower stratospheric cooling which is presumably attributed to the lack of proper stratospheric ozone prescription, anthropogenic forcings and coarse vertical resolution. 


\section{b. Probabilistic forecast verification}

Evaluating the model's ability to predict ENSO phases probabilistically provides additional insight into the models ability to capture important modes of variability. The model testing is done here in a setting that mimics a true operational forecasting approach. First we present typical examples of forecast plumes for the 1982 and 1988 ElNiño and La-Niña events respectively as illustrated in Fig. 13, and it can be seen that the coupled model successfully captures the development and maturity of these two typical ENSO episodes.

In a probabilistic verification framework for seasonal forecasting, the observed and predicted fields are often separated into three categories of above-normal, nearnormal and below-normal conditions based on pre-defined thresholds emanated from model history (climatology). Despite that ENSO (anomalous and neutral) is a relatively more predictable component of the climate system, results from the near-normal category are omitted here owing to the low skill generally associated with this category in other variables such as surface temperature and rainfall (Van den Dool and Toth 1991). In addition, the signature of neutral ENSO is not as influential as anomalous ENSO when used as a predictor in a statistical remapping framework (e.g. Landman and Beraki, 2012). This categorization, results in a $2 \times 2$ contingency table. The contingency tables are subsequently used to compute the reliability diagrams, relative operating characteristics (ROC) curves, area underneath of the ROC curve and other commonly used measures of probabilistic skill such as the Brier (Skill) Score.

The ROC is a highly flexible method for representing the quality of dichotomous, categorical and probabilistic forecasts (Mason \& Graham, 1999). It is derived from 
Signal Detection Theory (SDT) which was first introduced to the Meteorological community by Mason (1982). The ROC curve (Swets 1973; Mason 1982; Harvey et al. 1992) is derived from a contingency table (Wilks 2006) in which the hit rate and the false-alarm rate are compared. In probabilistic forecasting system, a warning can be issued when the forecast for a predefined event exceeds some threshold (Mason 1979). Optimally, the ROC curve is desired to lie toward the upper most left corner of a ROC diagram. The diagonal line represents no skill and a curve lays below the no skill line implies that the forecasting system is not better than guess work. The area under the ROC curve is computed numerically and normalized to constitute what is referred to as a ROC score. The ROC score of a skillful forecasting system always exceeds the 0.5 limit.

It is worthwhile mentioning, however, that the ROC is not sensitive to biases (systematic or nonsystematic; Murphy 1988) that may be embedded in the forecast system. This implies that a biased forecast can still produce a good ROC curve. It is useful to view the ROC as measure of potential skill and is often accompanied by a corresponding reliability diagrams. Reliability diagram is a type of conditional distribution which shows given each forecast probability interval, how frequently observation actually ended up in one or another category (Hartmann et al. 2002). The reliability diagram is constructed from the computation of the hit rate for the set of forecasts for individual probability bins separately and then plotted against the corresponding forecast probabilities. The most reliable forecasting systems have curves in close proximity of the diagonal line of perfect reliability.

The ROC and reliability diagrams curves were calculated for each forecast leadtime. Fig. 14 shows diagrams for three lead-months (1-,3- and 6- month lead-times) to 
describe the model performance. The corresponding frequency histograms showing the relative frequency of use of the forecast bins which are also referred to as "sharpness diagrams" both for below- and above-normal are shown on the top-left and bottom-right corners of each plot respectively. These histograms reveal how strongly and frequently the issued forecast probabilities depart from the climatological probabilities. At a1-month lead-time, the model exhibits good reliability to predict both the cold and warm phases of ENSO during late austral summer (December) although it shows a tendency of over forecast relative to the latter. It suggests that the quality of forecast manifested in the ROC curves is attainable as the forecasting system is unbiased where the strength is more robust for the cold phase category. At a 3-month lead-time the model reveals fairly high reliability to predict both cold and warm phases at lower probability bins, but gradually diverges to be over and under forecast for warmer and colder categories at higher probabilities respectively. The model still has good reliability at a 6 month lead-time in spite of both categories being overpredicted. During the start of the austral winter (Fig. 15), the model exhibits high reliability to predict both the cold and warm phases of ENSO at 1- and at 3-month lead-times. Notwithstanding, at a 6-month lead-time the reliability of the model becomes weak. The deterioration of skill at this lead-time and longer is also captured in the AC (Fig. 1) and is presumably attributed as suggested earlier to the spring barrier. It is more evident from both Fig. 14 and Fig. 15 that in the Niño-3.4 region, cold events are more skilfully predicted compared to warm events. These results are similar to that found in previous ENSO predictability studies (Kirtman 2003; D05).

The global distributions of ROC scores demonstrated by the OAGCM during the austral summer based on the November hindcasts predicting years of wet and dry 
conditions are shown in Fig. 16. Only those scores which are statistically significant at 95\% are shown. The significance test is conducted using a variant of the Mann-Whitney non-parametric procedure that explicitly accounts for variance adjustment caused by incidents of ties (Mason and Graham 2002; Wilks 2006). It is apparent that the OAGCM is successful in discriminating below- and above-normal rainfall conditions over the larger part of the globe. Maximum skill is obtained on the equatorial Pacific region across all lead-times. Similar skill patterns are demonstrated for the larger part of southern Africa ranging from ROC sores of predominantly 0.6 to patches of 0.8 . Similarly, the global surface temperature ROC score distribution of the coupled model is further demonstrated in Fig. 17. This verification result suggests that the model is able to significantly discriminate cold and warm episodes over the larger part of the globe. The performance of the model is more consistent and stronger in predicting surface temperatures than rainfall probabilistically, a result also found in other models (Barnston and Smith 1996; Colman and Davey 1999). These global results also support what has been discussed above with respect to the reliability diagrams for the southern Africa region in the sense that the model is more reliable in providing cold and warm events as opposed to dry and wet.

Fig. 18 shows the reliability diagrams obtained from the different initialized model hindcasts for unusually warm and cold events in the vicinity of the austral summer (DJF) at 1-3 months lead-times. The sharpness diagram both for below- and abovenormal are also shown on the top-left and bottom-right corners of each plot respectively. The model is reliably discriminating warm and cold episodes with virtually no skill deterioration as a function of lead-time. At higher probabilities, however, the model 
exhibits a slight tendency of overconfidence despite the model being increasingly conservative in providing warnings at higher probability bins as shown in the sharpness diagrams. The model also demonstrates similar skill levels during the January to March and the November to January seasons. Notwithstanding, the OAGCM has generally shown a tendency of issuing warnings of certain events while such events (dry or wet condition; Fig. 19) are less frequently observed in the southern African region during the austral summer. The skill of the OAGCM in predicting surface temperature probabilistically, as one may expect, is by far more reliable than the rainfall forecasts where the model generally suffers from overconfidence. Nevertheless, the weakness is presumably attributed to the fact that the model is not equally successful across the whole of southern Africa as shown in Fig. 16. Besides, the overconfidence bias is apparently caused by rainfall conditions of higher seasonal totals (right tail of the scatter diagram; Fig. 19). The reliability and scatter analysis used identical inputs and both considered the contribution of each grid point and each ensemble member (no spatial average was applied). Previous studies (e.g., Landman et al. 2012; Landman and Beraki 2012) have similarly suggested that the most common slope of the reliability curves found for seasonal rainfall forecasts for the region are shallower than the diagonal line.

\section{Summary and conclusions}

Coupled climate models represent the state of the art of seasonal forecasting which inherently renders them to be exceptionally convenient for seasonal climate prediction purposes. Notwithstanding, owing to the enormous computational needs of and complexity associated with OAGCMs, their engagement for seasonal forecasts in South Africa was initially not considered feasible particularly in an operational environment. 
The substantial augmentation of the computational resources in South Africa due to the resent CHPC intervention brought new hope to South African climate modellers. Founded mainly on this motivation, we attempted to explore the advantage of coupled climate models in the area of research and seasonal forecast production. The emergence of the ECHAM4.5-MOM3-SA OAGCM in South Africa is the first ever locally developed coupled climate model which is configured for seasonal forecasts production. Moreover, it employs an initialization strategy that capitalizes on the best available atmospheric information, thusly making the forecasting system uniquely different from previous coupled models using the same atmosphere and ocean models.

The model evaluation in the context of ENSO forecast showed that the OAGCM was plausibly skillful in most instances in capturing the development and maturity of ElNiño and La-Niña episodes up to an 8 moth lead-time. The result was also complemented by low error concentrations confined within the range of 0.1 to $0.5 \mathrm{RMSE}$. In a probabilistic sense, the analysis revealed that La-Niña events are more skillfully discriminated than La-Niño events by the model. However, the model skill was generally found to decay faster during the spring barrier.

The model intercomparison revealed that the ECHAM4.5-MOM3-SA OAGCM demonstrated comparable level of skill for the Niño-3.4 region SST forecast with stateof-the-art coupled models administered by other international centres such as the UKMO, MF, ECMWF and CFS-NCEP, IRI and locally developed CCA based statistical model (MMS). The initialization strategy introduced in the ECHAM4.5-MOM3-SA configuration found to be beneficial when the seasonal variation of ENSO attains its peak 
as opposed to the D05 version. This result is rather encouraging and further implies that the proposed forecasting system is robust.

Further verification analysis confirmed that the coupled model demonstrated remarkable skill up to several month lead-times in predicting the equatorial IOD during the period spanning between the mid austral spring and the start of the main summer seasons which reaches its peak in November. This may suggest that IOD is more predictable when its seasonal variation becomes strong. The investigation also unveiled that the weakness of the model in other seasons was mainly caused by the western segment of the dipole which eventually contaminates the DMI although the cause of the deficiency is not clear. The complexity of the equatorial IOD prediction reportedly challenges coupled climate models even though observational and theoretical studies conclusively demonstrated the role of the dipole structure in modulating southern Africa and Australian rainfall variability at the seasonal timescale.

The ECHAM4.5-MOM3-SA was also found to be successful in simulating the observed upper air circulation as represented by the 850 and $500 \mathrm{hPa} \mathrm{GH}$ in the equatorial belt with a pronounced skill on the latter. Further south, the model was fairly skilful on those key ocean basins such as SPW and SAM despite that the model was mostly unable to outscore a climatological forecast. In addition, the model is fairly skillful in simulating the lower tropospheric and upper stratospheric equatorial flow during the austral summer. Notwithstanding the zonal wind appeared to be more predicable than the meridional wind that might be attributed to ENSO forcing.

The OAGCM probabilistic forecast for the austral summer season for rainfall totals and surface air temperatures was found to be informative and fairly useful. The 
model was evidently successful in discriminating below- and above-normal rainfall conditions over the larger part of the globe where the signal is more pronounced on the equatorial Pacific region. Similarly, the verification result indicated that the model was able to discriminate cold and warm episodes. Nonetheless, as one may expect, the performance of the model was more consistent and more skilful in predicting surface air temperatures than rainfall totals probabilistically. The findings is further supported, at least for the southern African window, by the fact that the model is more reliable in issuing forecasts of cold or warm seasons as opposed to dry or wet. Probabilistic rainfall forecasts are biased toward overconfidence.

The advent of fully coupled ocean-atmosphere models (e.g., Stockdale et al. 1998) promised improved seasonal forecasts. However, in spite of the promise of enhanced seasonal forecast skill, coupled models have not been administered in South Africa for operational seasonal forecast production because these models effectively require double the computing resources of their atmosphere-only counterparts. Recent advances in computing infrastructures in South Africa and the support from international institutions such as the IRI in developing the coupled model described here have paved the way for utilising and for further development of such state-of-the-art coupled models for seasonal forecast production and research.

Acknowledgments. The work is financially supported by the Water Research Commission (WRC) and Applied Centre for Climate \& Earth Systems Science (ACCESS). The Authors are also gratefully appreciative for the CHPC computational support. Uwe Schulzweida of the Max-Planck-Institut für Meteorologie (MPI) has kindly 
provided the ECHAM4.5 AGCM code. This work has benefitted from comments from Nico Kroese and anonymous reviewers. The work was also impossible without the atmosphere and ocean data assimilation products respectively of NCEP and GFDL and the GFDL ocean model. 


\section{References}

Alves, J. O. S., M.A. Balmaseda, D. L. T. Anderson, and T. N.

Stockdale, 2004: Sensitivity of dynamical seasonal forecasts to ocean initial conditions. Quart. J. Roy. Meteor. Soc., 130, 647-668.

Balmaseda, M., and D. Anderson, 2009: Impact of initialization strategies and observations on seasonal forecast skill. Geophys. Res. Lett., 36, L01701, doi:10.1029/2008GL035561.

Barnston, A. G., and T. M. Smith, 1996: Specification and Prediction of Global Surface Temperature and Precipitation from Global SST Using CCA. J. Climate, 9, 26602697.

Beraki, A.F., W.A. Landman, D.G. DeWitt, C. Olivier, K. Mathole, T. Ndarana, 2012: Modelled Sea-Surface Temperature Scenario Considerations and Southern African Seasonal Rainfall and Temperature Predictability. In press.Water Research Commission Rep. xxxx/x/xx, 127 pp.

Brinkop. S., and E. Roeckner, 1995: Sensitivity of a general circulation model to parameterizations of cloud-turbulence interactions in the atmospheric boundary layer. Tellus,47A, 197-220.

Colman, A. and M. Davey, 1999: Prediction of summer temperature, rainfall and pressure in Europe from preceding winter North Atlantic Ocean temperature. Int. J. Climatol., 19, 513-536. doi: 10.1002/(SICI)1097-0088(199904)19:5<513::AIDJOC370>3.0.CO;2-D 
Collins, D.C., C.J. Reason, and F. Tangang, 2004: Predictability of Indian Ocean sea surface temperature using canonical correlation analysis. Climate Dyn., 22, 481-497.

Conil, S., H. Douville and S. Tyteca, 2009: Contribution of realistic soil moisture initial conditions to boreal summer climate predictability. Climate Dyn., 32, 75-93.

Derber J., and A. Rosati, 1989: A global oceanic data assimilation system. J. Phys. Oceanogr., 19, 1333-1347.

Déqué, M., 2001: Seasonal predictability of tropical rainfall: Probabilistic formulation and validation. Tellus, 53A, 500-512.

DeWitt, D. G. 2005: Retrospective forecasts of interannual Sea Surface Temperature anomalies from 1982 to present using a directly coupled Atmosphere-Ocean General Circulation Model. Mon. Wea. Rev., 133, 2972-2995.

Doblas-Reyes, F.J., J. Garcia-Serrano, F. Lienert, A.P. Biescas and L.R.L. Rodrigues, 2013: Seasonal climate predictability and forecasting: status and prospects. WIRES Clim Change 2013, 4, 245-268. doi: 10.1002/wcc.217.

Douville, H., 2010: Relative contribution of soil moisture and snow mass to seasonal climate predictability: A pilot study. Climate Dyn., 34, 797-818.

Dümenil, L., and E. Todini, 1992: A rainfall-runoff scheme for use in the Hamburg climate model. Advances in theoretical hydrology. J. P. O'Kane, Ed.,Elsevier, 129157. 
Fan Y., and H. van den Dool, 2004: Climate Prediction Center global monthly soil moisture data set at $0.5^{\circ}$ resolution for 1948 to present. J. Geophys. Res., 109, D10102, doi:10.1029/2003JD004345.

Fouquart, Y., and B. Bonnel, 1980: Computations of solar heating of the earth's atmosphere: A new parameterization. Beitr. Phys. Atmos., 53, 35-62.

Ji, Ming, David W. Behringer, Ants Leetmaa, 1998: An Improved Coupled Model for ENSO Prediction and Implications for Ocean Initialization. Part II: The Coupled Model. Mon. Wea. Rev., 126, 1022-1034.

Gaertner, M.A., and M. Castro, 1996: A new method for vertical interpolation of the mass field. Mon. Wea. Rev., 124, 1596-1603.

Gent, P.R., and J. C. McWilliams, 1990: Isopycnal mixing in ocean circulation models. $J$. Phys. Oceanogr., 20, 150-155.

Goddard, L., S. J. Mason, S. E. Zebiak, C. F. Ropelewski, R, Basher, and M. A. Cane, 2001: Current approaches to seasonal-to-interannual climate predictions. Int. J.Climatol., 21, 1111-1152.

Graham, R. J., M. Gordon, P. J. McLean, S. Ineson, M. R. Huddleston, M. K. Davey, A. Brookshaw, and R. T. H. Barnes, 2005: A performance comparison of coupled and uncoupled versions of the Met Office seasonal prediction general circulation model. Tellus, 57A, 320-319. 
Gregory, D., J. J. Morcrette, C. Jakob, A. C. M. Beljaars, and T. Stockdale, 2000:

Revision of convection, radiation and cloud schemes in the ECMWF Integrated Forecasting System. Quart. J. Roy. Meteor. Soc., 126,1685-1710.

Guérémy. J. F., M. Déqué, A. Braun, and J. P. Piedelièvre, 2005: Actual and potential skill of seasonal predictions using the CNRM contribution to DEMETER: coupled versus uncoupled model. Tellus, 57A, 308-319.

Hartmann, H. C., T. C. Pagano, S. Sorooshian, R. Bales, 2002: Confidence builders: Evaluating seasonal climate forecasts for user perspectives. Bull. Amer. Meteor. Soc., 83, 683-698.

Harvey, L. O., K. R. Hammond, C. M. Lusk, and E. F. Mross, 1992: The application of signal detection theory to weather forecasting behavior. Mon. Wea. Rev., 120; 863883.

Hoffman, R.N., and E. Kalnay,.1983: Lagged average forecasting, an alternative to Monte Carlo forecasting. Tellus, 35A, 100-118.

Kanamitsu, M., A. Kumar, J. K. Schemm, H. M. H. Juang, W. Wang, F. Yang, S. Y. Hong, P. Peng, W. Chen, and M. Ji, 2002: NCEP dynamical seasonal forecast system 2000. Bull. Amer. Meteor. Soc., 83: 1019-1337.

Kirtman, B. P., J. Shukla, B. Huang, Z. Zhu, E. K. Schneider, 1997: Multiseasonal Predictions with a coupled tropical ocean-global atmosphere system. Mon. Wea. Rev., 125, 789-808. 
B. P., 2003: The COLA anomaly coupled model: Ensemble ENSO prediction.

Mon. Wea. Rev., 131, 2324-2341.

Komori, N., A. Kuwano-Yoshida, T. Enomoto, H. Sasaki, and W. Ohfuchi, 2008: HighResolution Simulation of the Global Coupled Atmosphere-Ocean System:

Description and Preliminary Outcomes of CFES (CGCM for the Earth

Simulator). High Resolution Numerical Modelling of the Atmosphere and Ocean. K.

Hamilton W. Ohfuchi, Ed., Springer, 241-260.

Koster, R. D., M. J. Suarez, P. Liu, U. Jambor, A. Berg, M. Kistler, R. Reichle, M. Rodell, and J. Famiglietti, 2004: Realistic initialization of land surface states: Impacts on subseasonal forecast skill. J. Hydrometeor., 5, 1049-1063.

Landman, W. A., and S. J. Mason, 2001: Forecasts of near-global sea surface temperatures using canonical correlation analysis. J. Climate, 14: 3819-3833.

, F. Engelbrecht, A. Beraki, C. Engelbrecht, M. Mbedzi, T. Gill, and L. Ntsangwane, 2009: Model output statistics applied to multi-model ensemble long-range forecasts over South Africa. Water Research Commission Rep. 1492/1/08, 56 pp. , and A. Beraki, 2012: Multi-model forecast skill for mid-summer rainfall over southern Africa. Int. J. Climatol., 32, 303-314.

, D. DeWitt, D-E. Lee, A. Beraki, and D. Lötter, 2012: Seasonal rainfall prediction skill over South Africa: 1- vs. 2-tiered forecasting systems. Wea. Forecasting, 27, 489-501. 
Large, W. G., J. C. McWilliams, and S. C. Doney, 1994: Oceanic vertical mixing: A review and a model with a nonlocal boundary layer parameterization. Rev. Geophys., 32, 363-403.

Laursen L, and E. Eliasen, 1989: On the effects of the damping mechanisms in an atmospheric general circulation model. Tellus, 41A, 385-400.

Louis, J. F., 1979: A parametric model of vertical eddy fluxes in the atmosphere. Bound.Layer Meteor., 17, 187-202.

Majewski, D. 1985: Balanced initial and boundary values for a limited area model. Beitr. Phys. Atmosph., 58, 147-159.

Mason, I. 1979: On reducing probability forecasts to yes/no forecasts. Mon. Wea. Rev., 107, 207-211.

_ 1982: A model for assessment of weather forecasts. Aust. Meteor. Mag., 30, 291303.

Mason, S.J., and N.E. Graham, 2002: Areas beneath the relative operating characteristics (ROC) and relative operating levels (ROL) curves: statistical significance and interpretation. Quart. J. Roy. Meteoro. Soc., 128, 2145-2166.

Mathole, K., T. Ndarana, A.F. Beraki and W. A. Landman, 2013: Assessing the Importance of Lower Stratospheric Processes on the Predictability of Summer Rainfall over South Africa. SAJS, Accepted.

McGregor, J. L., 1996: Semi-Lagrangian advection on conformal-cubic grids. Mon. Wea. Rev., 124, 1311-1322. 
Miller, M.J., T. N. Palmer, and R. Swinbank, 1989: Parameterization and influence of sub-grid scale orography in general circulation and numerical weather prediction models. Meteor. Atmos. Phys., 40, 84-109.

Mo, K.C.n and M. Ghil, 1987: Statistics and dynamics of persistent anomalies. J. Atmos. Sci., 44, 877-901.

Morcrette J-J, L. Smith and emperature dependence of the absorption in longwave radiation parameterizations. Beitr. Phys. Atmosph., 59, 455-469.

Murphy, A.H., 1988: Skill Scores Based on the Mean Square Error and Their Relationships to the Correlation Coefficient. Mon. Wea. Rev., 116, 2417-2424.

New, M., M. Hulme, and P. D. Jones, 2000: Representing twentieth century space-time climate variability. Part 2: development of 1901-96 monthly grids of terrestrial surface climate. J. Climate, 13, 2217-2238.

Nordeng, T. E., 1994: Extended versions of the convective parameterization scheme at ECMWF and their impact on the mean and transient activity of the model in the Tropics. ECMWF Research Department Tech. Memo. 206, European Centre for Medium-Range Weather Forecasts, 41 pp.

Pacanowski, R. C., and S. M. Griffes, 1998: MOM 3.0 manual. NOAA/Geophysical Fluid Dynamics Laboratory, Princeton, NJ, 608 pp.

Palmer, T. N., and D. L. T. Anderson. 1994: The prospects for seasonal forecasting-A review paper. Quart. .J. Roy. Meteor. Soc., 120, 755-793. 
, and Coauthors, 2004: Development of a European Multimodel Ensemble System for Seasonal-to-Interannual Prediction (DEMETER). Bull. Amer. Meteor. Soc., 85, 853-872.

Pope, V. D., M. Gallani, P. R. Rowntree, and R. A. Stratton, 2000: The impact of new physical parametrizations in the Hadley Centre climate model-HadAM3. Climate Dyn., 16, 123-146.

Reason, C. J. C., 1999: Interannual warm and cool events in the subtropical/mid-latitude South Indian Ocean region. Geophys. Res. Lett.., 26, 215-218.

_, C.J.C., W. Landman, and W. Tennant, 2006: Seasonal to Decadal Prediction of Southern African Climate and Its Links with Variability of the Atlantic Ocean. Bull. Amer. Meteor. Soc., 87, 941-955.

and H.M. Mulenga, 1999: Relationships between South African rainfall and SST anomalies in the South West Indian Ocean. Int. J. Climatol., 19, 1651-1673.

— 2002: Sensitivity of the southern African circulation to dipole SST patterns in the South Indian Ocean. Int. J. Climatol., 22, 377-393.

Redi, M. H., 1982: Oceanic isopycnal mixing by coordinate rotation. J. Phys. Oceanogr., 12, 1155-1158.

Reynolds, R. W., N. A. Rayner, T. M. Smith, and D. C. Stokes, 2002: An improved in situ and satellite SST analysis for climate. J. Climate, 15, 1609-1625. 
Roeckner, E., and Coauthors, 1996: Simulation of present-day climate with the ECHAM4 model: Impact of model physics and resolution. Max Planck Institute for Meteorology Rep. 93, Hamburg, Germany, 171 pp.

Saha, S., and Coauthors, 2006: The NCEP Climate Forecast System. J. Climate, 19, 3483-3517.

Saji, N. H, B. N. Goswami, P. N. Vinayachandran, and T. Yamagata, 1999: A dipole mode in the tropical Indian Ocean. Nature 401, 360-363.

Schneider, E. K., D. G. DeWitt, A. Rosati, B. P. Kirtman, L. Ji, and J. J Tribbia. 2003: Retrospective ENSO forecasts: Sensitivity to atmospheric model and ocean resolution. Mon. Wea. Rev., 131, 3038-3060.

Sellers, P. J., Y. Mintz, Y. C. Sud, and A. Dalcher. 1986: A Simplified Biosphere Model (SiB) for use within general circulation model. J. Atmos. Sci., 43, $505-531$.

Shen, R., E. R. Reiter, and J. F. Bresch, 1986: A simplified hydrodynamic mesoscale model suitable for use over high plateau regions. Meteor. Atmos. Phys., 34, 251-296

Simmons, A. J., and D. M. Burridge, 1981: An energy and angular-momentum conserving vertical finite difference scheme and hybrid vertical coordinates. Mon. Wea. Rev., 109, 758-766.

Simmons, A. J., D. M. Burridge, M. Jarraud, C. Girard, and W. Wergen, 1989: The ECMWF medium-range prediction models: Development of the numerical formulations and the impact of increased resolution. Meteor. Atmos. Phys. 40, 28-60. 
Smagorinsky, J., 1963: General circulation experiments with the primitive equations: I.

The basic experiment. Mon. Wea. Rev., 91, 99-164.

Stockdale, T. N., D. L. T. Anderson, J. O. S. Alves, and M. Balmaseda, 1998: Global seasonal rainfall forecasts using a coupled ocean-atmosphere model. Nature, $\mathbf{3 9 2 ,}$ 370-373.

O. Alves, G. Boer, M. Deque, Y. Ding, A. Kumar, K. Kumar, W. Landman, S.

Mason, P. Nobre, A. Scaife, O. Tomoaki, and W.-T. Yun, 2009: Understanding and

Predicting Seasonal to Interannual Climate Variability - the producer perspective.

World Climate Conference 3, Geneva, Switzerland, 31 August - 4 September 2009.)

Swets, J. A., 1973: The relative operating characteristic in psychology. Science, 182, $990-1000$.

Taylor, K.E., 2001: Summarizing multiple aspects of model performance in a single diagram. J. Geophys. Res., 106, 7183-7192.

Terray, L., A. Piacentini, and S. Valcke, 1999: OASIS 2.3, Ocean Atmosphere Sea Ice Soil: User's guide. CERFACS Tech. Rep. TR/CMGC/99/37, Toulouse, France, 82 pp. [Available online at http://www.cerfacs.fr/3-25801-Technical-Reports.php.]

Tiedtke, M., 1989: A comprehensive mass flux scheme for cumulus parameterization in largescale models. Mon. Wea. Rev., 117, 1779-1800.

Undén, P., and Coauthors, 2002: HIRLAM-5 Scientific Documentation, Sveriges meteorologiska och hydrologiska institut (SMHI), 144 pp. 
Van den Dool, H., and Z. Toth, 1991: Why do forecasts for "near normal”, often fail? Wea. Forecasting, 6, 76-85.

Walker, J., and P. R. Rowntree, 1977: The effect of soil moisture on circulation and rainfall in a tropical model. Quart. .J. Roy. Meteor. Soc., 103, 29-46.

Wang, G., R. Kleeman, N. Smith, and F. Tseitkin, 2002: The BMRC coupled general circulation model ENSO forecast system. Mon. Wea. Rev., 130, 975-991.

Washington, R., and A. Preston, 2006: Extreme wet years over southern Africa: Role of the Indian Ocean sea surface temperatures. J. Geophys. Res., 111, D15104, doi:10.1029/2005JD006724.

Williamson, D. L., and P.J. Rasch, 1994: Water vapor transport in the NCAR CCM2. Tellus, 46A, 34-51

Wilks, D. S., 2006: Statistical Methods in the Atmospheric Sciences. 2nd ed. Academic Press, 627 pp.

Xie, P., and P. A. Arkin, 1997: Global precipitation: A 17-year monthly analysis based on gauge observations, satellite estimates and numerical model outputs. Bull. Amer. Meteor. Soc., 78: 2539-2558.

Yuan, X., and C. Li, 2008: Climate modes in southern high latitudes and their impacts on Antarctic sea ice, J. Geophys. Res., 113, C06S91, doi:10.1029/2006JC004067.

Zhao, M., and H.H. Hendon, 2009: Representation and prediction of the Indian Ocean dipole in the POAMA seasonal forecast model, Quart. J. Roy. Meteor. Soc., 135: $337-352$. 


\section{Tables:}

TABLE 1. OACGM skill and error growth in predicting the IOD for different leadmonths during late autumn and the beginning of summer seasons as measured by $\mathrm{AC}$ and RMSE respectively. The skill scores were computed against observed DMI computed from the OI SST. The * represents that AC is statistically significant at $95 \%$ level.

$\mathrm{AC}$

Lead

Oct

Nov

Dec

Oct

Nov

Dec

$\begin{array}{lllllll}0 & * 94.51 & * 92.75 & * 72.70 & 0.3645 & 0.2225 & 0.3472 \\ 1 & * 77.20 & * 83.21 & * 61.63 & 0.5526 & 0.4102 & 0.2692 \\ 2 & * 74.27 & * 77.29 & * 44.95 & 0.6036 & 0.4054 & 0.3054 \\ 3 & * 50.23 & * 77.61 & * 54.35 & 0.6894 & 0.4179 & 0.2844\end{array}$




$\begin{array}{rrrrrrr}4 & * 50.95 & * 59.99 & * 47.09 & 0.6852 & 0.4767 & 0.3214 \\ 5 & 31.36 & * 56.76 & * 47.84 & 0.7651 & 0.4887 & 0.3134 \\ 6 & 14.77 & * 45.63 & * 44.60 & 0.8535 & 0.5325 & 0.3255 \\ 7 & 10.35 & 38.19 & 28.26 & 0.8844 & 0.5712 & 0.3733 \\ 8 & 12.40 & 38.22 & 38.53 & 0.8485 & 0.6142 & 0.3518\end{array}$

\section{Figure Caption List}

FIG. 1. OAGCM Skill for the SST forecasts in the Niño3.4 as measured with AC as a function of lead-time (vertical) and target (horizontal) months based on the monthly mean SST over the period 1982-2009.

FIG. 2. OAGCM overall accuracy predicting the Niño3.4 SST. The RMSE is computed based on the monthly mean SST over the period 1982-2009

FIG. 3. OAGCM Skill for the SST forecasts in the Niño3.4 as measured with AC as a function of lead-time (vertical) and target (horizontal) months based on the monthly mean SST over the period 1982-2009.

FIG. 4. Near global SST skill (AC) of the OAGCM during the start of the austral summer (December) for 6 months lead-time (0-5). Only statistical significant at $95 \%$ are shown.

FIG. 5. Same as Fig. 4 but for the austral winter (June). 
FIG. 6. Anomaly correlation by various prediction methods of monthly mean for the Niño-3.4 forecasts as a function of different lead-month (horizontal). The skill scores are base on the November (a) and February (b) initialized hindcasts. The ECHAM4.5MOM3-SA is denoted by SCM; The MMS refers to CCA based statistical Multi-Model ENSO prediction system.

FIG. 7. RMSE by various prediction methods of monthly mean for the Niño-3.4 forecasts as a function of different lead-month (horizontal). The level of bias in each model computed using the November (a) and February (b) initialized hindcasts. The ECHAM4.5-MOM3-SA (as in Fig. 6) compared with the local CCA based empirical model, DEMETER coupled models (UKMO, ECMWF and MF) and CFS of NCEP coupled model.

FIG. 8. Seasonal cycle of the standard deviation of anomalies of (a) the DMI and (b) the Niño3.4 index at various lead-months (as shown in the inset). Anomalies are computed by removing the respective climatological seasonal cycle for each lead-time and observations.

FIG. 9. Taylor diagram (Taylor 2001) by various prediction methods (as shown in the inset) based on the ensemble mean for SOI (Southern Oscillation index;*), IOD (solid circle) and rainfall totals for Tropical region between $20 \mathrm{oS}$ and $20 \mathrm{oN}$ (open circle ) and southern Africa south of the Equator (+). The standard deviation is normalized by the respective observation (see text). The ECHAM4.5-MOM3-SA is denoted by SCM.

FIG. 10. Time series of IOD index from the mid austral spring to the start of summer at 2,5 and 8 months lead for the period of 1982-2009. The OAGCM ensemble spread is 
shown by the box-whisker representation with $25 \%$ and $75 \%$ percentile of the ensemble members. The blue dots and green stars represent the ensemble mean and OI SST respectively. The blue (ensemble mean) and green (OISST) lines around the zero black line also depict the historical quartiles based on 28 years of the index.

FIG. 11. Actual skill of November initialized OAGCM integrations both for $850 \mathrm{hPa}$ (left panel) and 500hPa (right panel) geopotential heights. (a,b) NDJ (0-month lead-time), (c,d) DJF (1-month lead-time) and (e,f) JFM (2-month lead-time). The MSSS is computed against the NCEP/DOE upper air climate data as a proxy for observation and climatological forecast as a reference. The PSA indicated with * on the three locations (H1, H2 and H3; Yuan and Li 2008).

FIG. 12. Anomaly correlation of zonal (a) and meridional (b) mean wind anomalies of the equatorial region $\left(20^{\circ}\right.$ So to $\left.20^{\circ} \mathrm{N}\right)$ at various lead-times as a function of pressure levels.

FIG. 13. ECHAM4.5-MOM3-SA forecast plume of Niño-3.4 SST anomalies (K) initialized from the $10 \mathrm{NCEP} / \mathrm{DOE}$ atmospheric initial states on the $4^{\text {th }}$ of April 1982 (top panel) and 1988 (lower panel). All members are shown in dot lines, the ensemble mean is solid line marked with closed circle, and the observation is in black line marked with triangle as shown in the legend.

FIG. 14. ROC curve (left panel) and reliability diagrams (right panel) of ECHAM4.5MOM3-SA probabilistic forecasts that show the warming and cooling phases of ENSO for different lead-times of February as shown on the title of each plot. "B" and " $\mathrm{A}$ " in the legend denote La Niña and El-Niño respectively. The histograms on the topleft (cold) and 
bottom right (warm) corners each reliability diagrams plots imply the frequency of forecast usage in different bins.

FIG. 15. as in Fig. 14 but June as the target month.

FIG. 16. Global Distribution of ROC area for seasonal rainfall totals (mm) skill of the OAGCM during the austral summer from NDJ (lead-0) to JFM (lead-2) both for below(a-c) and above-normal (d-f) categories. Only statistically significant values at the 95\% level shades are shown.

FIG. 17. As Fig. 16 but for $2 \mathrm{~m}$ surface temperatures (K).

FIG. 18. Reliability diagrams of the OAGCM in predicting below- and above-normal surface air temperature conditions during the three rolling seasons centred around the austral summer season for the southern African region (South of the Equator). "B" and "A" in the legend denote cold and warm events respectively. The frequency of utilization the different probability bins for both below- and above-normal categories are also shown on the left top-upper and bottom-left corners of each diagram respectively.

FIG. 19. Reliability diagrams (right panel) as in Fig 15 but for November initialized hindcasts rainfall totals. The scatter diagrams (right panel) used the same inputs as in the reliability diagrams; the ensembles members are shown in grey $(+)$ and the ensemble mean is in black (*). No spatial averaging is applied on the fields meaning that each grid point value is included in each plot. 


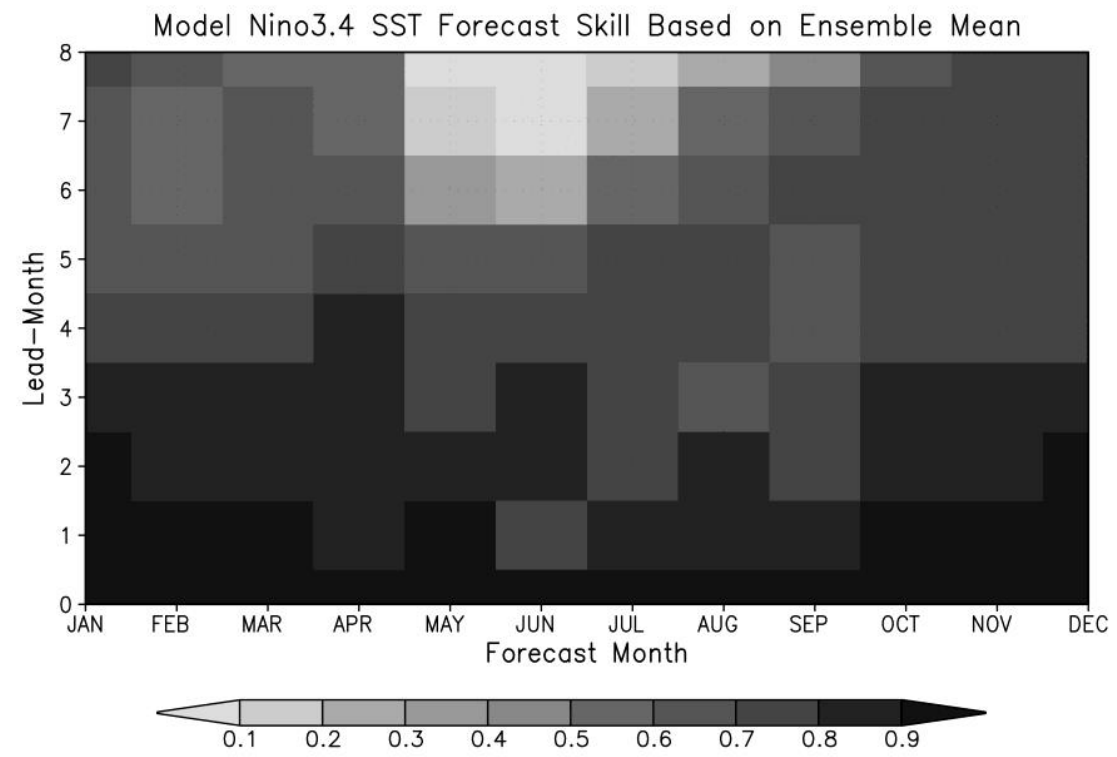

FIG. 1. OAGCM Skill for the SST forecasts in the Niño3.4 as measured with AC as a function of lead-time (vertical) and target (horizontal) months based on the monthly mean SST over the period 1982-2009. 

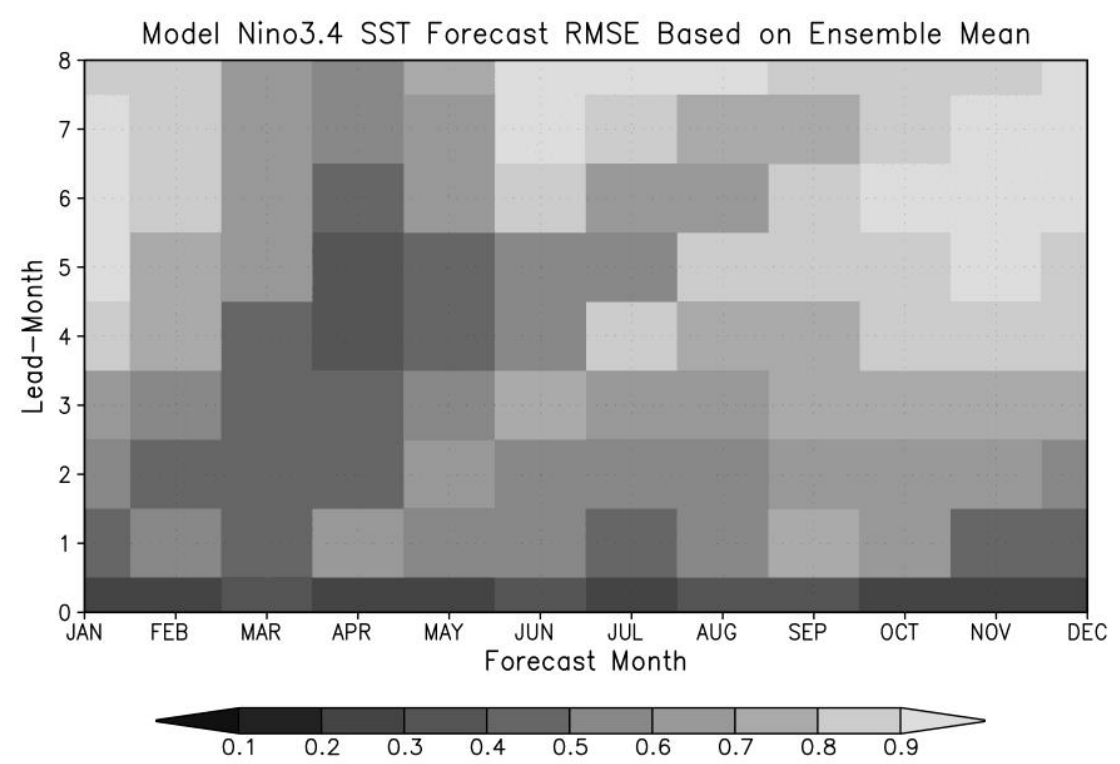

FIG. 2. OAGCM overall accuracy predicting the Niño3.4 SST. The RMSE is computed based on the monthly mean SST over the period 1982-2009 
(a) DJF Nino3.4 SST Forecasts

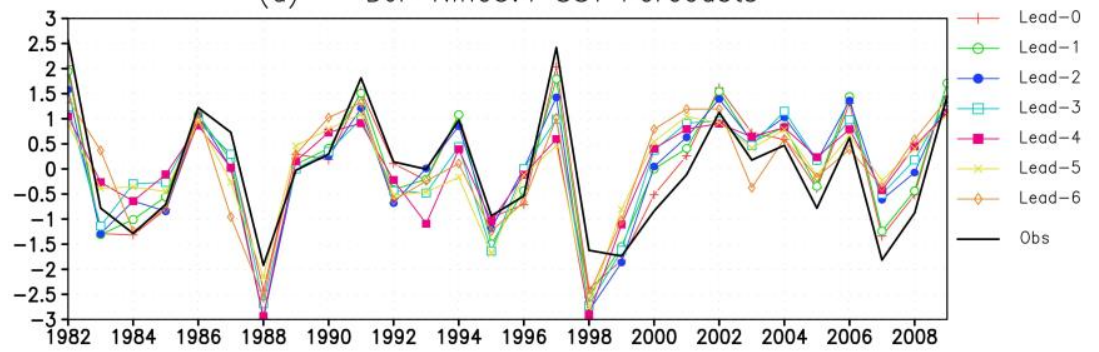

(b) SON Nino3.4 SST Forecasts

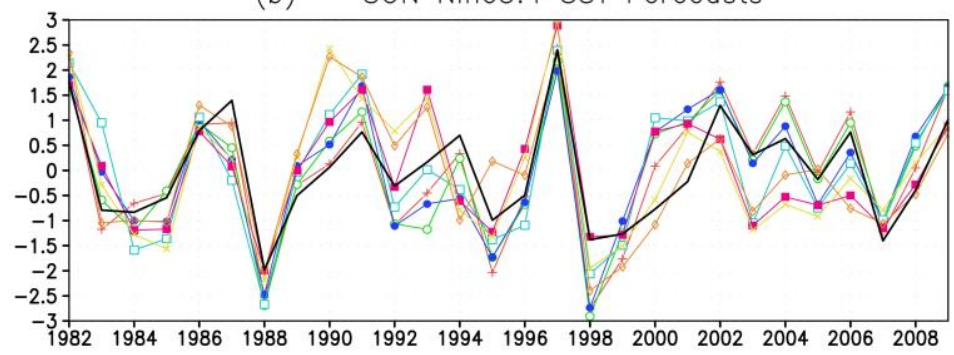

(c) JJA Nino3.4 SST Forecasts

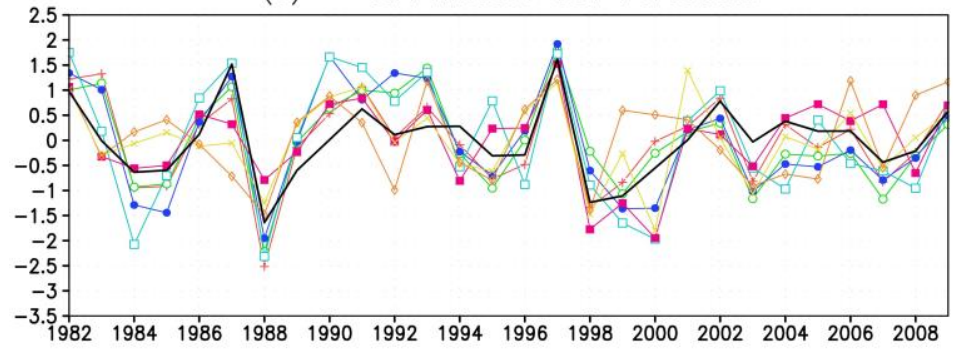

(d) MAM Nino3.4 SST Forecasts

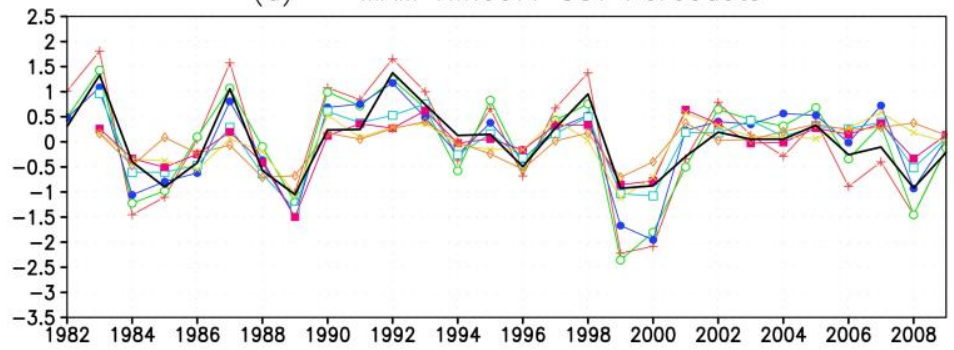

FIG. 3. The time evolution of El Niño Southern Oscillation (ENSO) as simulated by the ECHAM4.5-MOM3-SA ocean-atmosphere coupled climate model. 
(a)

(c)
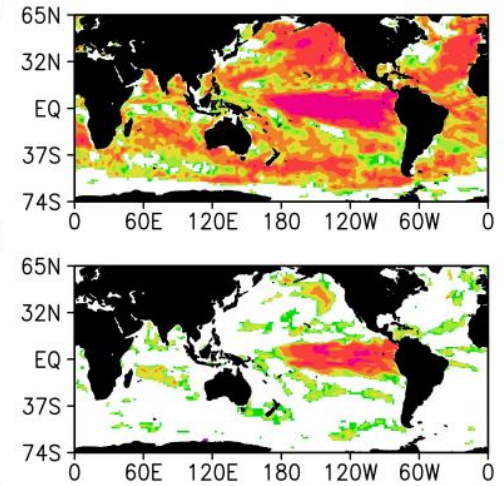

(e)

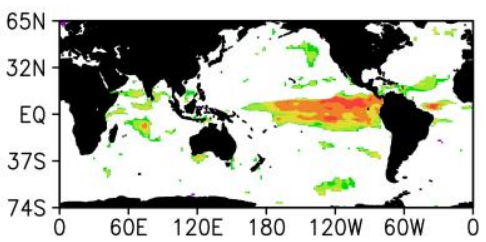

(b)

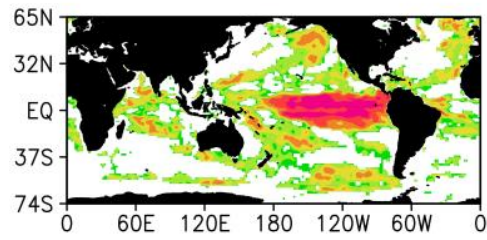

(d)

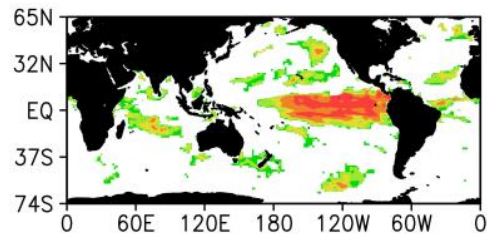

(f)

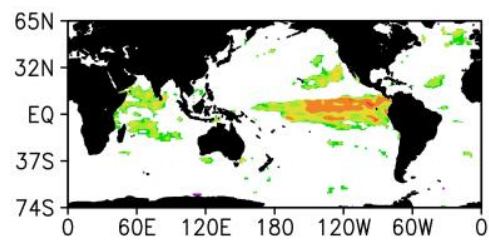

FIG. 4. Near global SST skill (AC) of the OAGCM during the start of the austral summer

(December) for 6 months lead-time (0-5). Only statistical significant at 95\% are shown.

(c)

(a)

(e)
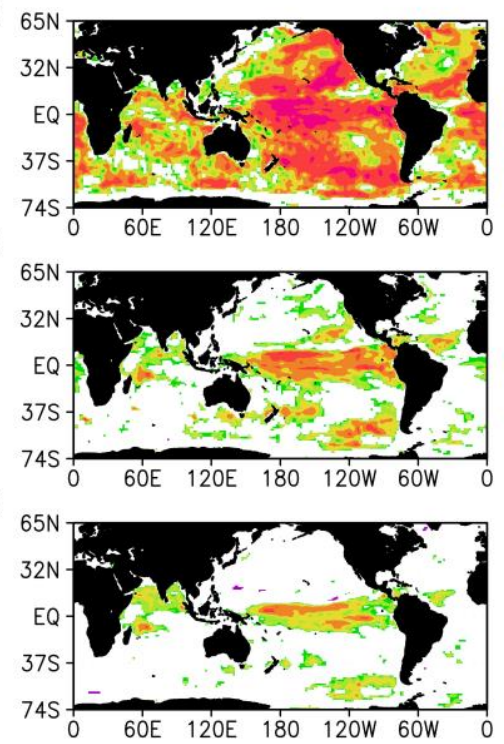

(b)

(d)

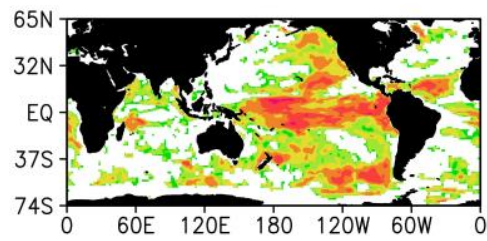

(f)
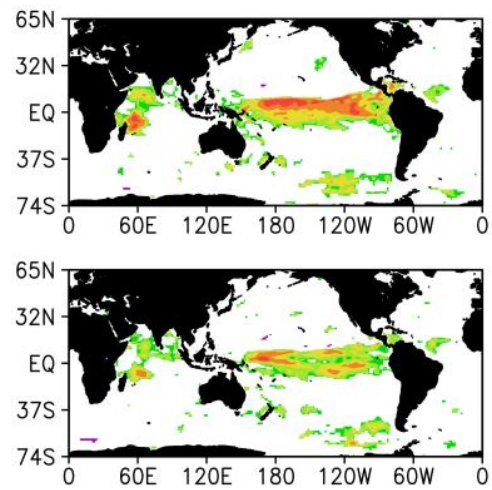

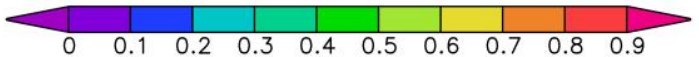


FIG. 5. Same as Fig. 4 but for the austral winter (June).

(a) Nino3.4 Skill Nov IC

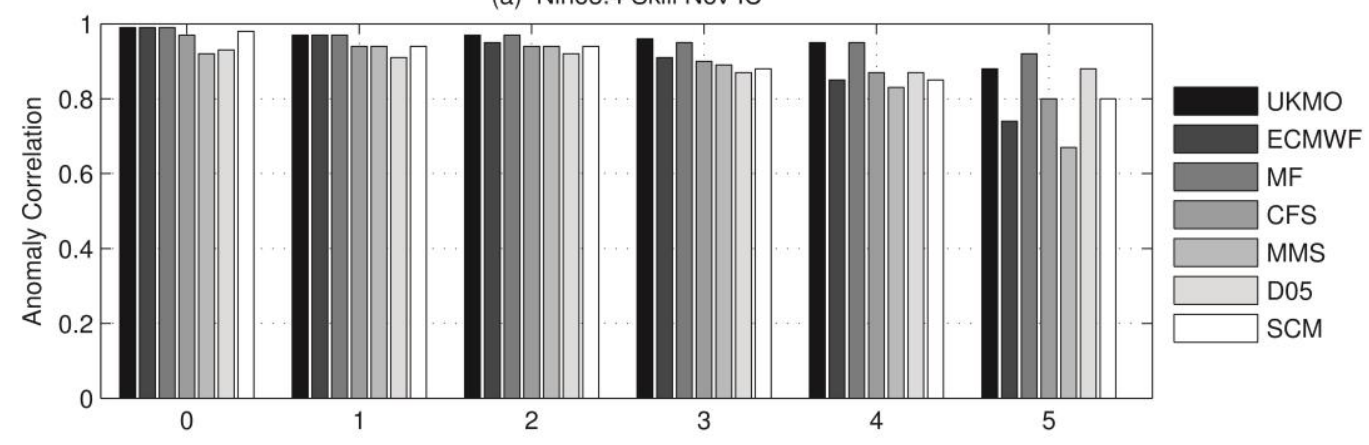

(b) Nino3.4 Skill Feb IC

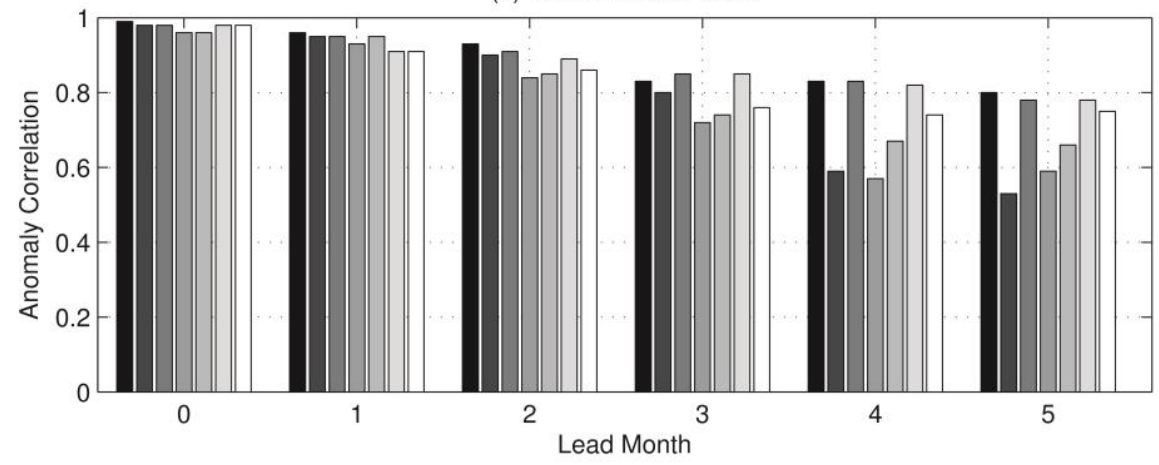

FIG. 6. Anomaly correlation by various prediction methods of monthly for the Niño-3.4 forecasts as a function of different lead-month (horizontal). The skill scores are base on the November (a) and February (b) initialized hindcasts. The ECHAM4.5-MOM3-SA is denoted by SCM; The MMS refers to CCA based statistical Multi-Model ENSO prediction system. 
(a) Nino3.4 Skill Nov IC

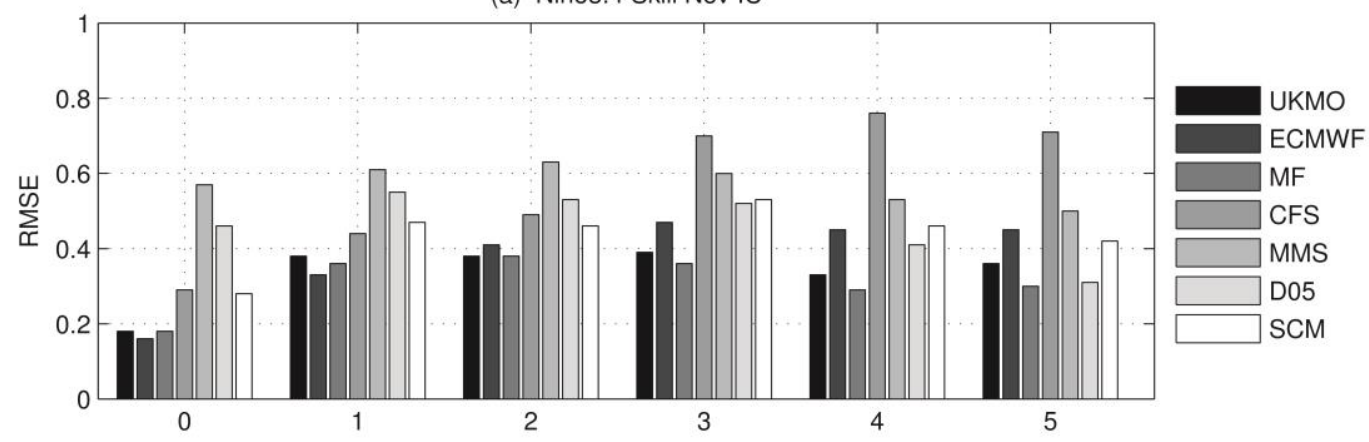

(b) Nino3.4 Skill Feb IC

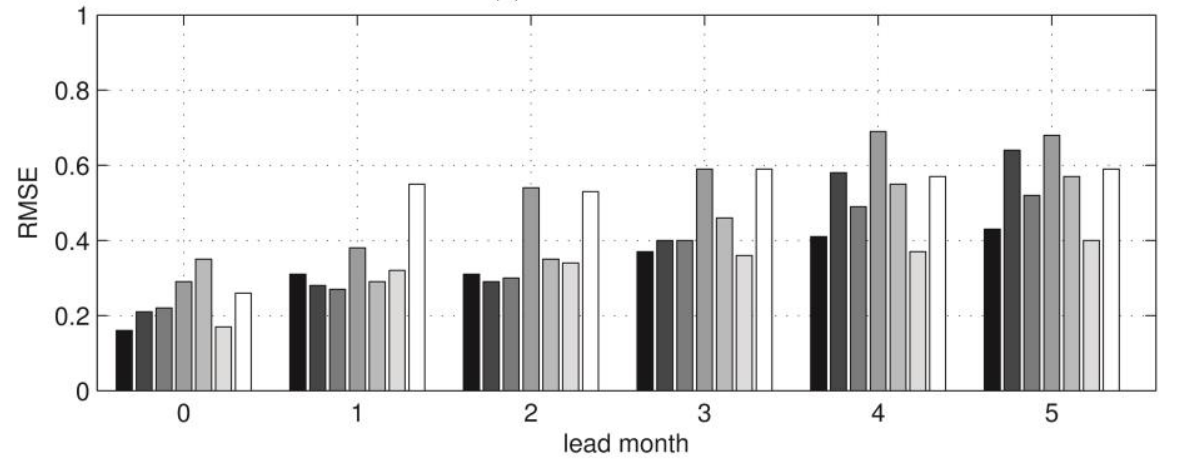

FIG. 7. RMSE by various prediction methods of monthly mean for the Niño-3.4 forecasts as a function of different lead-month (horizontal). The level of bias in each model computed using the November (a) and February (b) initialized hindcasts. The ECHAM4.5-MOM3-SA (as in Fig. 6) compared with the local CCA based empirical model, DEMETER coupled models (UKMO, ECMWF and MF), D05 and CFS of NCEP coupled model. 
(a)

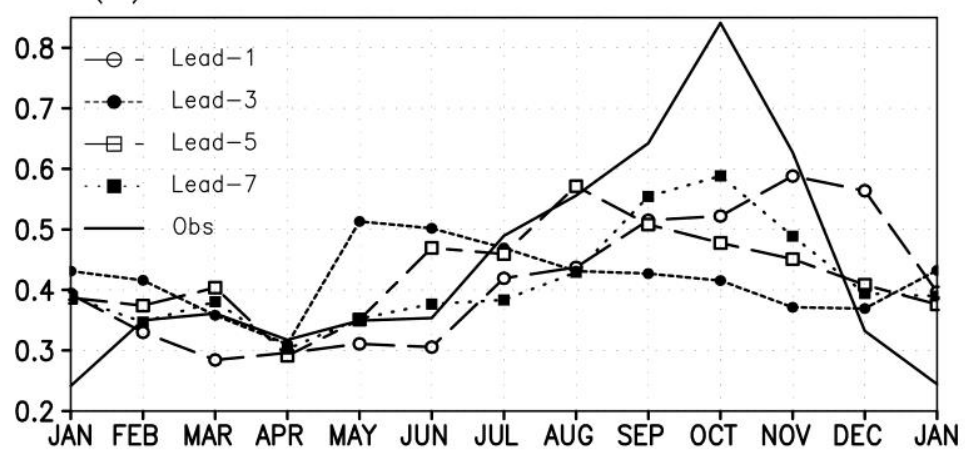

(b)

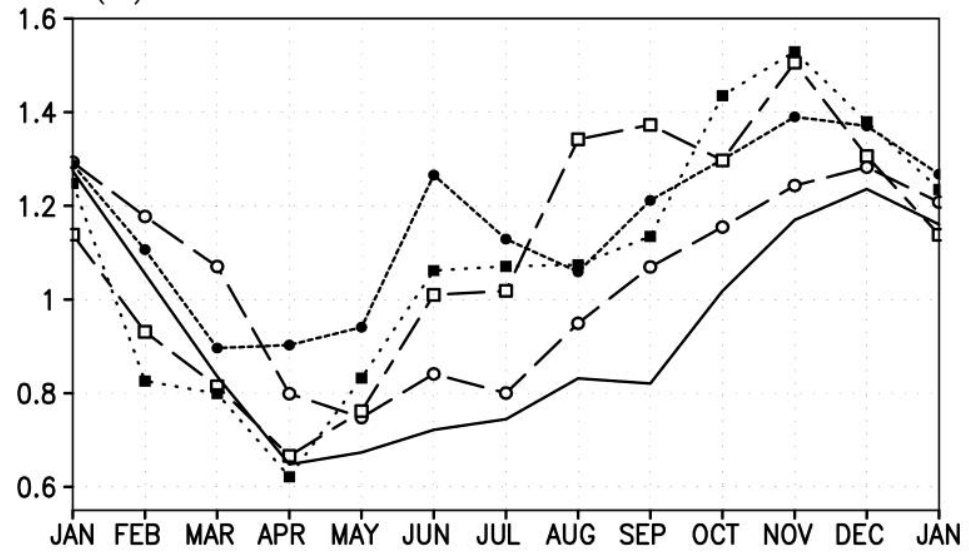

FIG. 8. Seasonal cycle of the standard deviation of anomalies of (a) the DMI and (b) the Niño3.4 index at various lead-months (as shown in the inset). Anomalies are computed formed by removing the respective climatological seasonal cycle each lead-time and observations. 


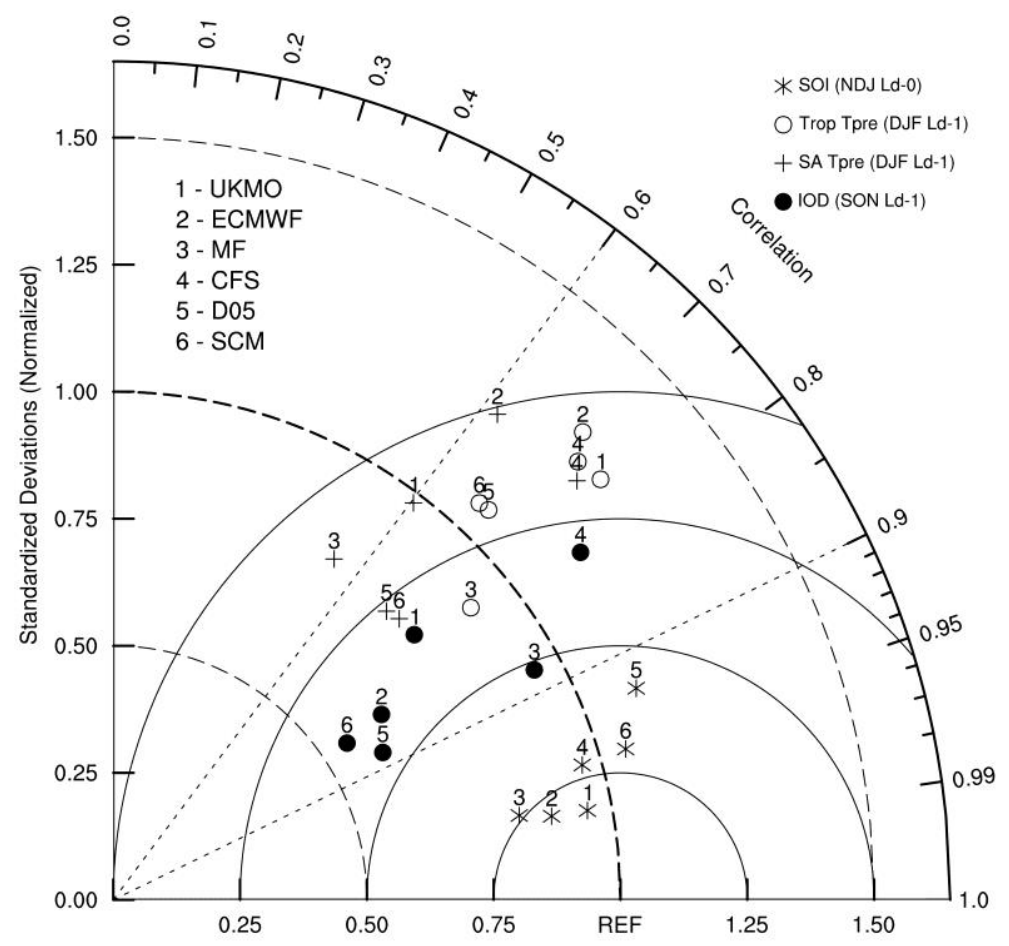

FIG. 9. Taylor diagram (Taylor 2001) by various prediction methods (as shown in the inset) based on the ensemble mean Niño-3.4 (*), IOD (solid circle) and rainfall totals for Tropical region between $20 \mathrm{oS}$ and $20 \mathrm{oN}(+)$ and southern Africa south of the Equator (open circle). The standard deviation is normalized by the respective observation (see text). The ECHAM4.5-MOM3-SA is denoted by SCM. 

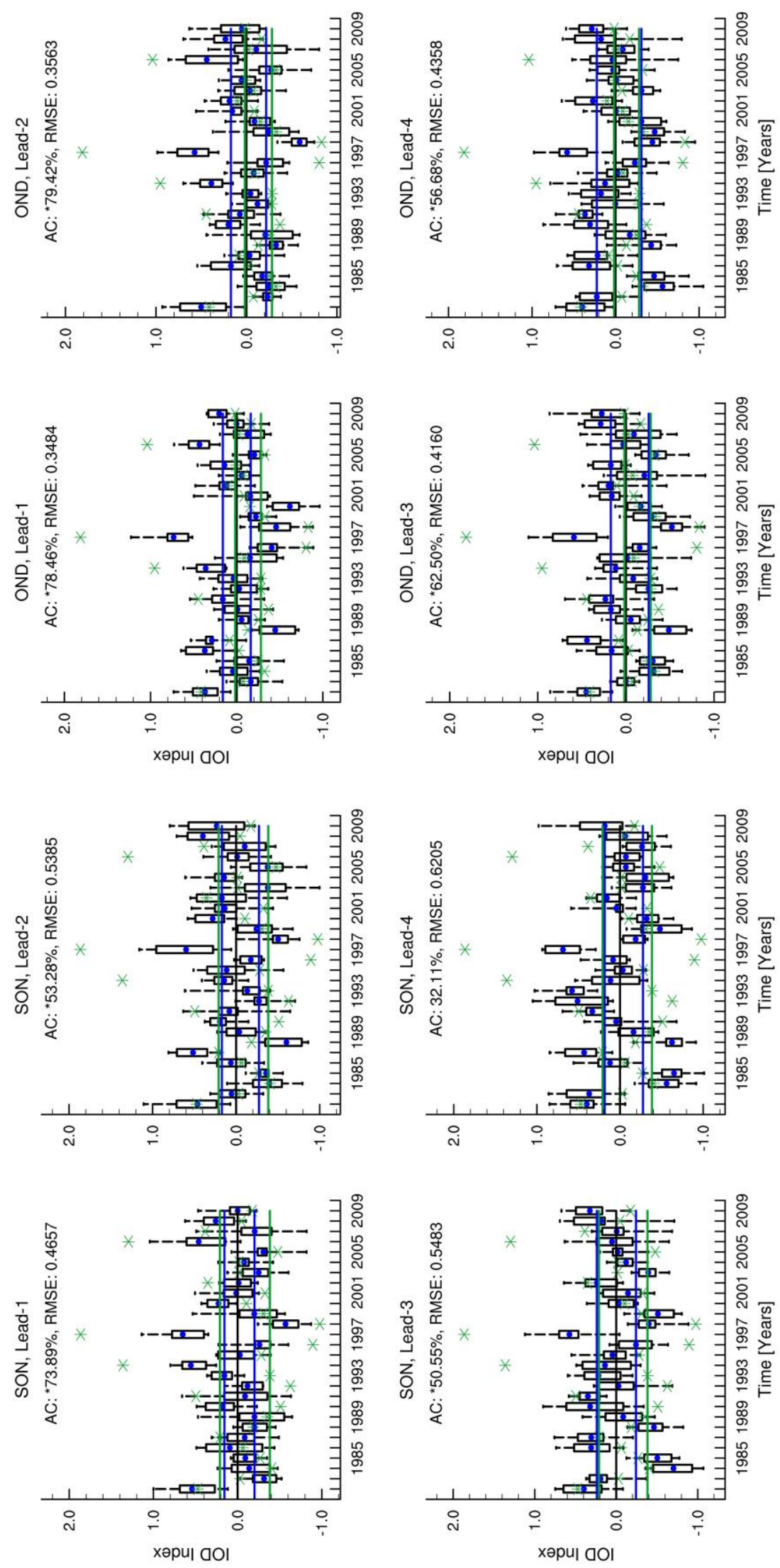
FIG. 10. Time series of IOD index from the mid austral spring to the start of summer at 2,5 and 8 months lead for the period of 1982-2009. The OAGCM ensemble spread is shown by the box-whisker representation with $25 \%$ and $75 \%$ terciles of the ensemble members. The blue dots and green stars represent the ensemble mean and OI SST respectively. The blue (ensemble mean) and green (OI SST) lines around zero black line also depict the historical quartiles based on 28 years of the index.

(a)

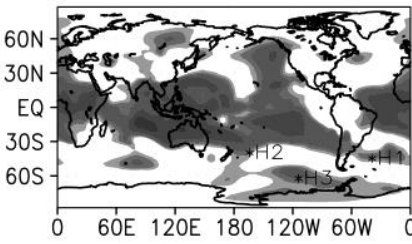

(c)

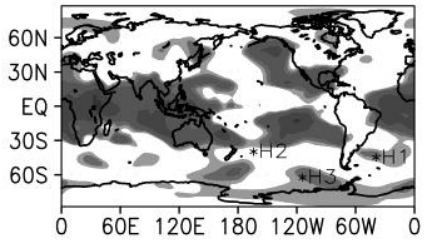

(e)

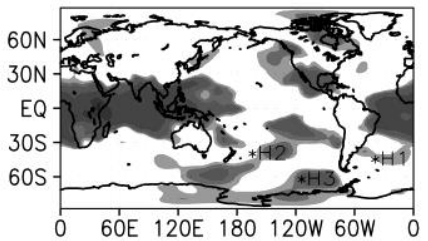

(b)

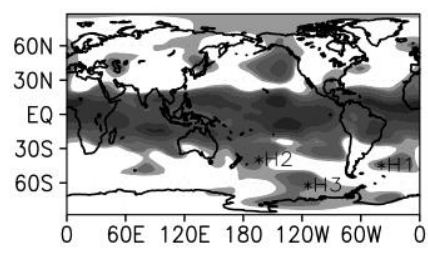

(d)

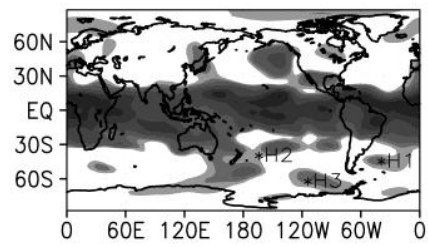

(f)

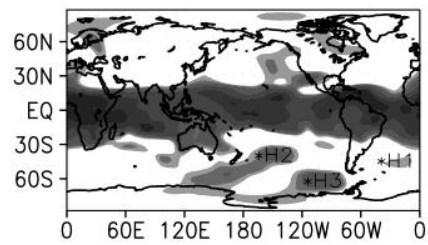

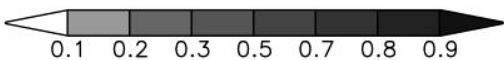

FIG. 11. Actual skill of November initialized OAGCM integrations both for $850 \mathrm{hPa}$ (left panel) and 500hPa (right panel) geopotential heights. (a,b) NDJ (0-month lead-time), (c,d) DJF (1-month lead-time) and (e,f) JFM (2-month lead-time). The MSSS is 
computed against the NCEP/DOE upper air climate data as a proxy for observation and climatological forecast as a reference. The PSA indicated with * on the three locations (H1, H2 and H3; Yuan and Li 2008).
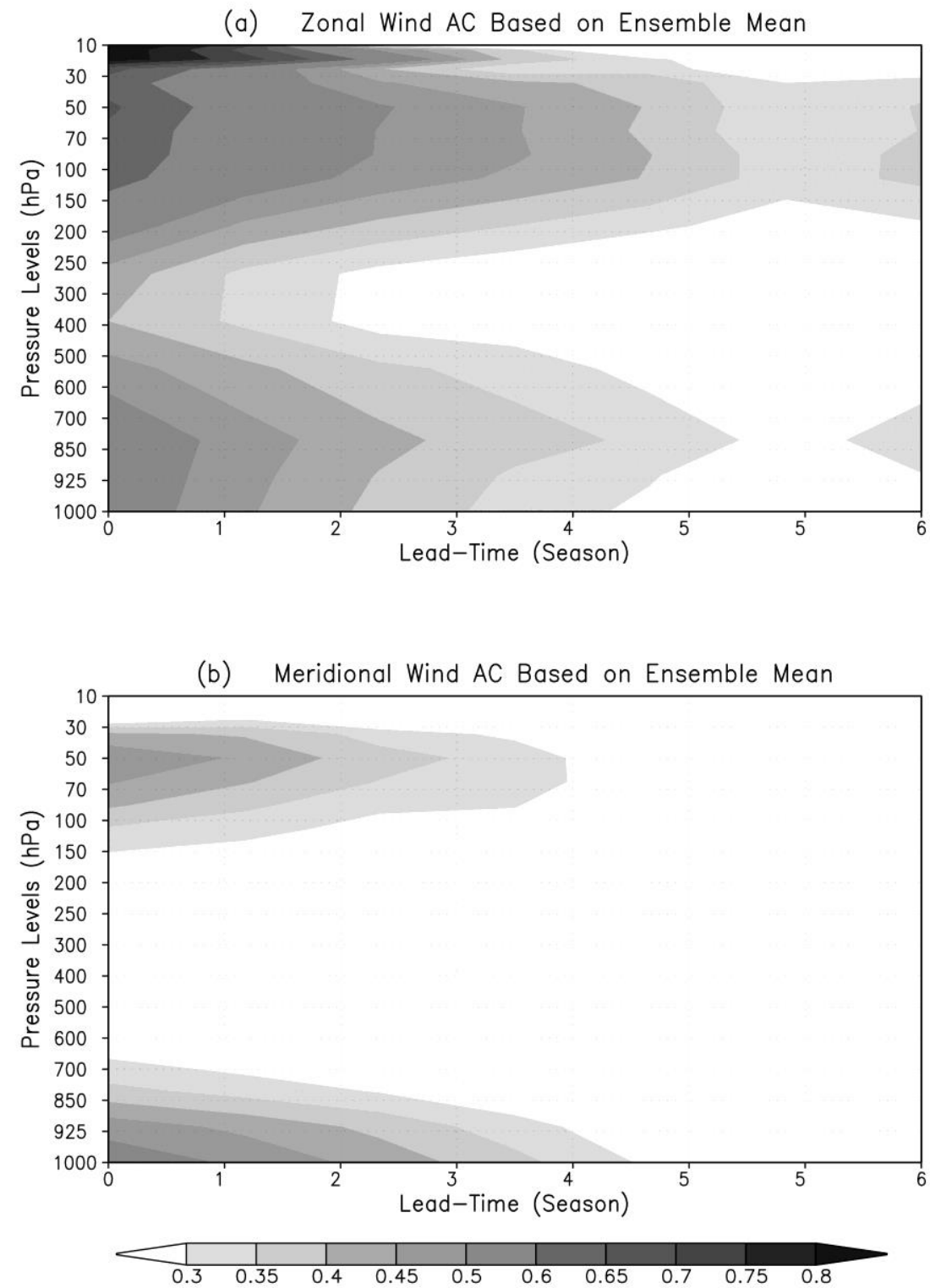
FIG. 12. Anomaly correlation of zonal (a) and meridional (b) mean wind anomalies of the equatorial region $\left(20^{\circ}\right.$ So to $\left.20^{\circ} \mathrm{N}\right)$ at various lead-time as a function of pressure levels.
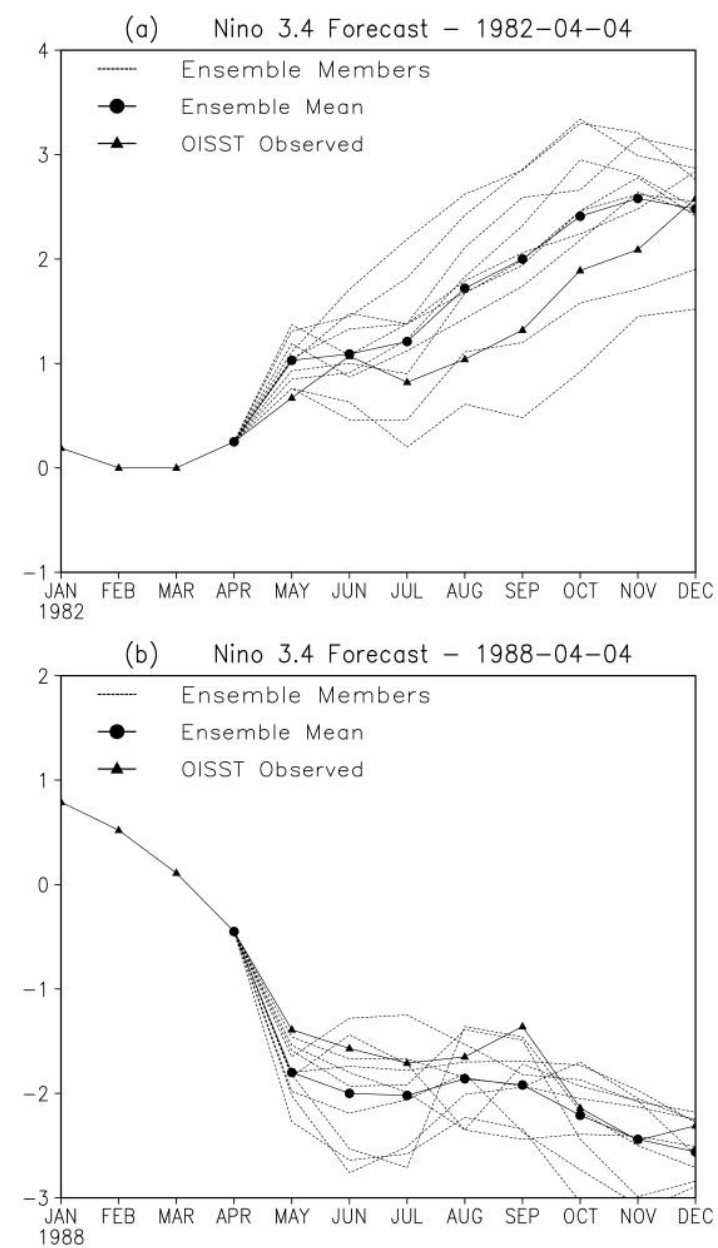

FIG. 13. ECHAM4.5-MOM3-SA forecast plume of Niño-3.4 SST anomalies (K) initialized from the 10 NCEP/DOE atmospheric initial states on the $4^{\text {th }}$ of April 1982 (top panel) and 1988 (lower panel). All members are shown in dot lines, the ensemble mean is solid line marked with closed circle, and the observation is in black line marked with triangle as shown in the legend. 

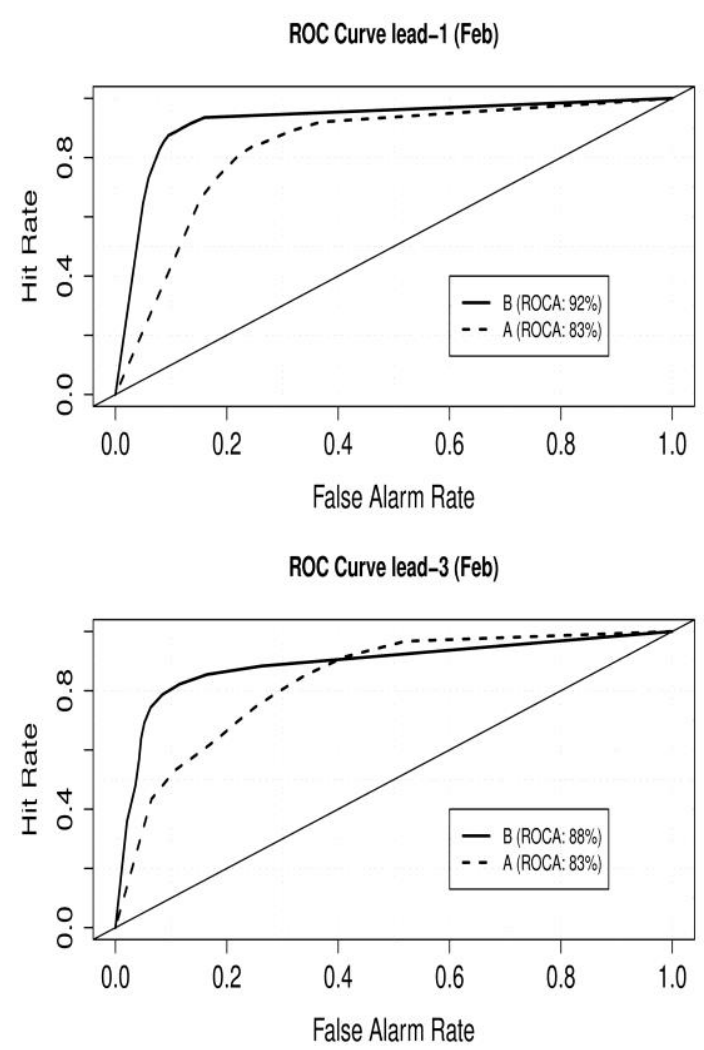

ROC Curve lead-6 (Feb)

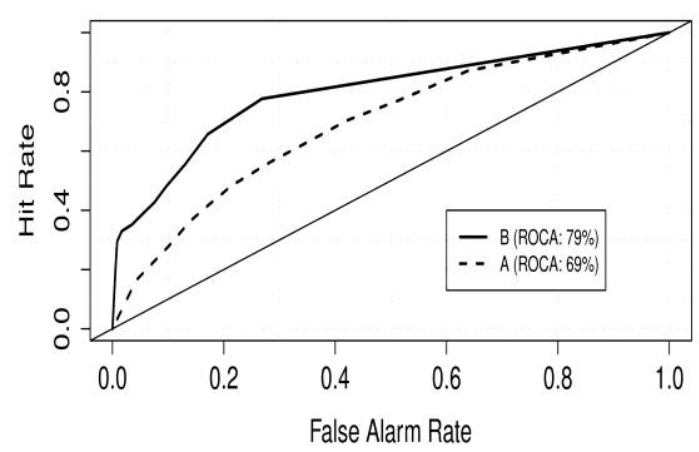

Relaiability Plot lead-1 (Feb)

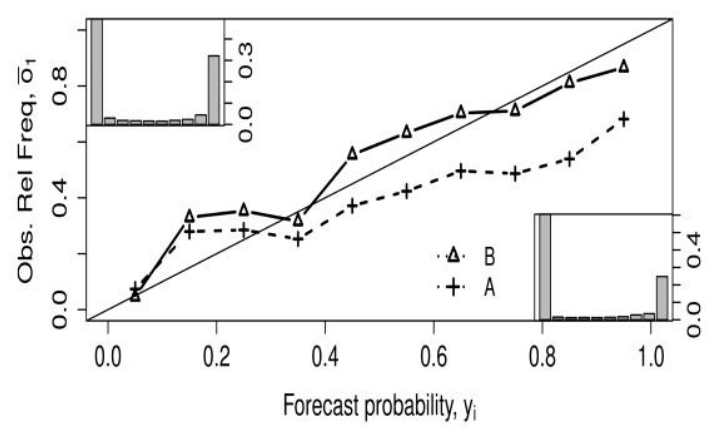

Relaiability Plot lead-3 (Feb)

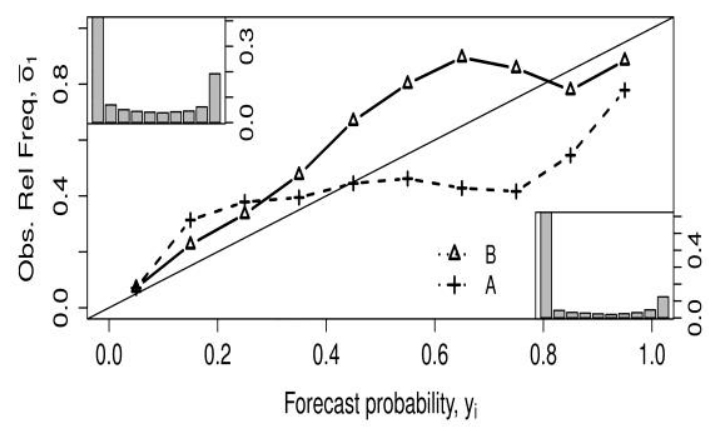

Relaiability Plot lead-6 (Feb)

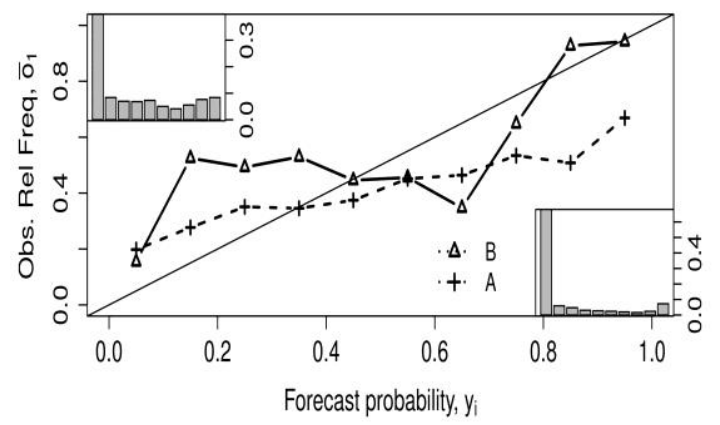

FIG. 14. ROC curve (left panel) and reliability diagrams (right panel) of ECHAM4.5-

MOM3-SA probabilistic forecasts that show the warming and cooling phases of ENSO for different lead-times of February as shown on the title of each plot. "B" and " $\mathrm{A}$ " in the legend denote La Niña and El-Niño respectively. The histograms on the topleft (cold) and 
bottom right (warm) corners each reliability diagrams plots imply the frequency of forecast usage in different bins.

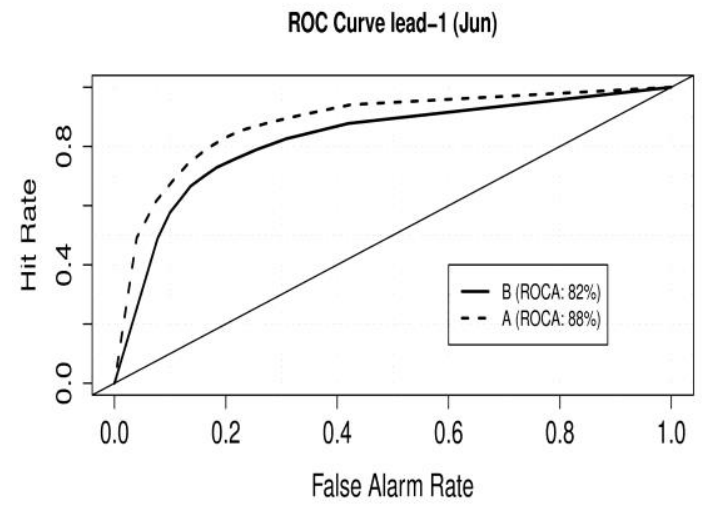

ROC Curve lead-3 (Jun)

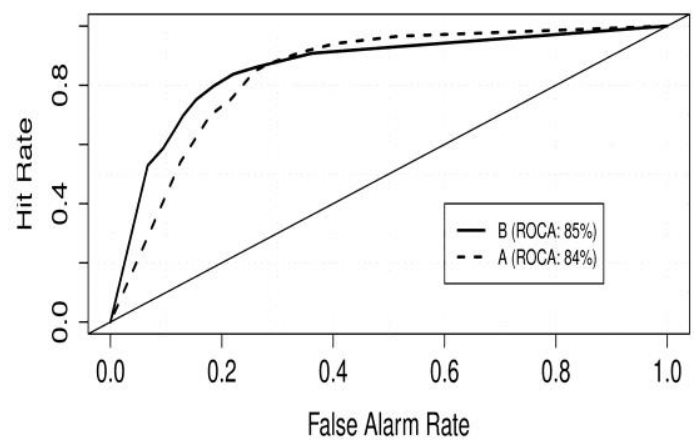

ROC Curve lead-6 (Jun)

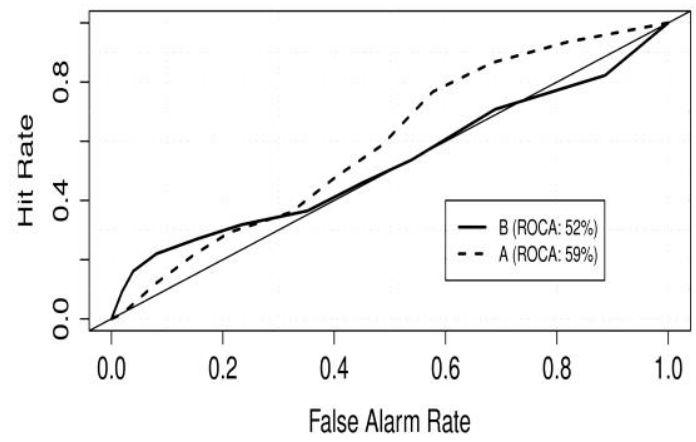

Relaiability Plot lead-1 (Jun)

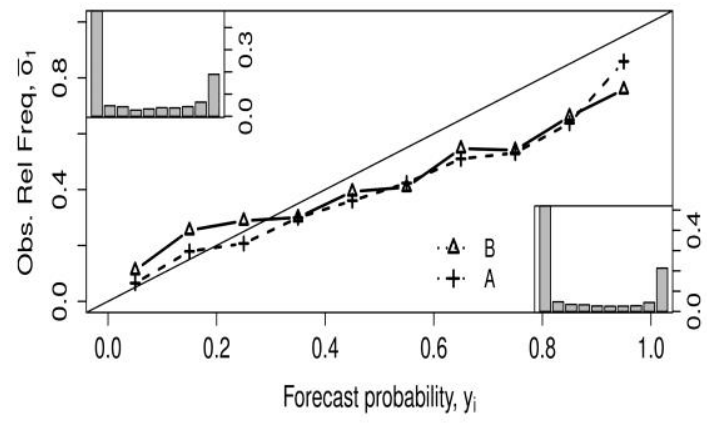

Relaiability Plot lead-3 (Jun)

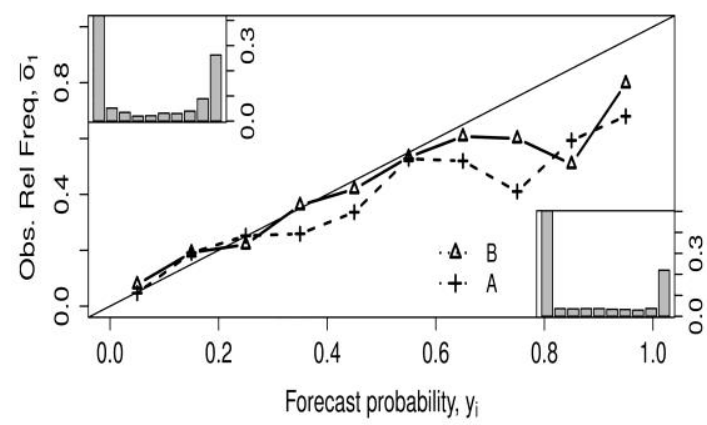

Relaiability Plot lead-6 (Jun)

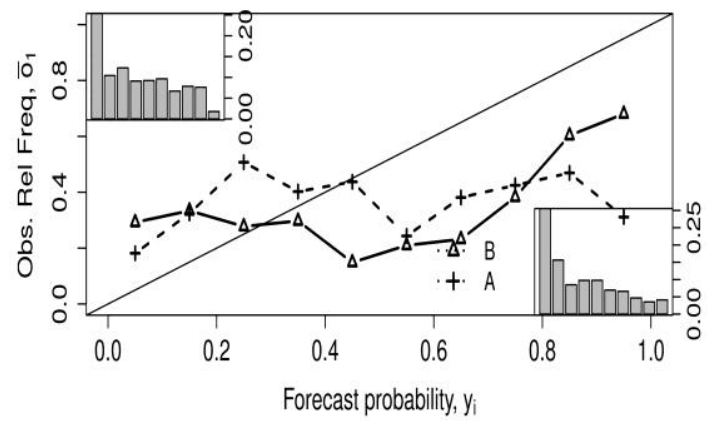

FIG. 15. as in Fig. 14 but June as the target month. 
(a)

(b)
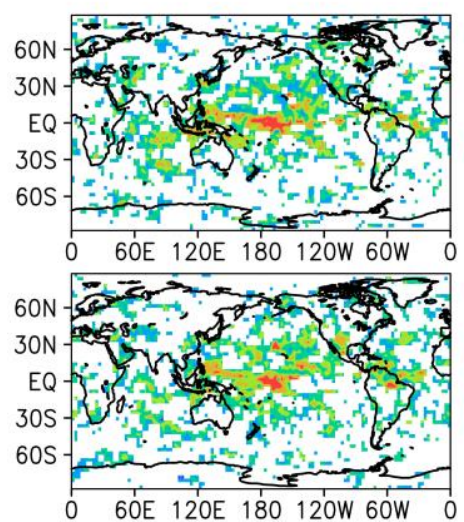

(c)

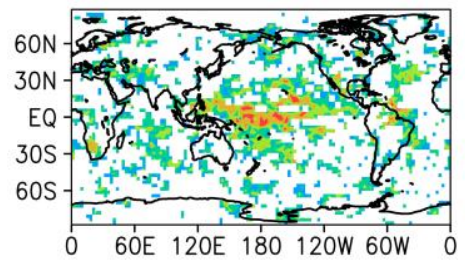

(d)

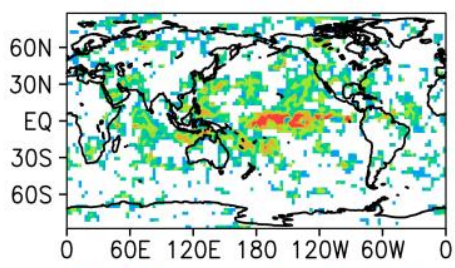

(e)

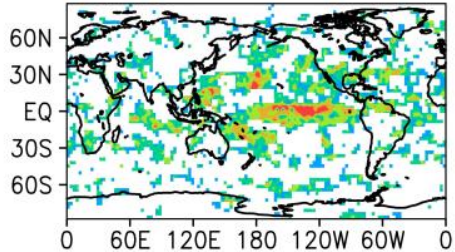

(f)

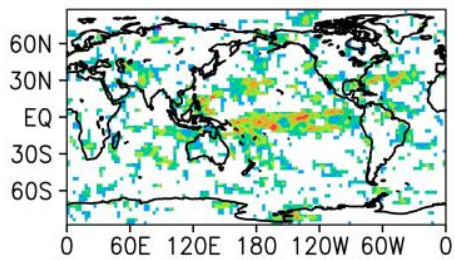

FIG. 16. Global Distribution of ROC area for seasonal rainfall totals (mm) skill of the

OAGCM during the austral summer from NDJ (lead-0) to JFM (lead-2) both for below(a-c) and above-normal (d-f) categories. Only statistically significant values at the 95\% level shades are shown. 
(a)

(b)
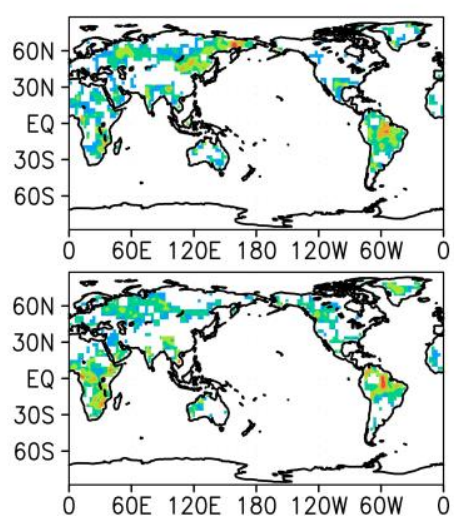

(c)

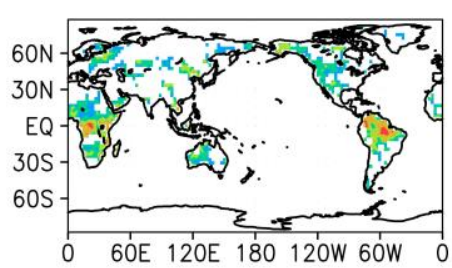

(d)

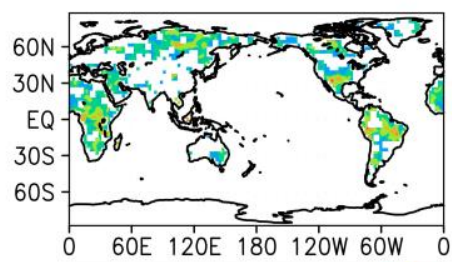

(e)

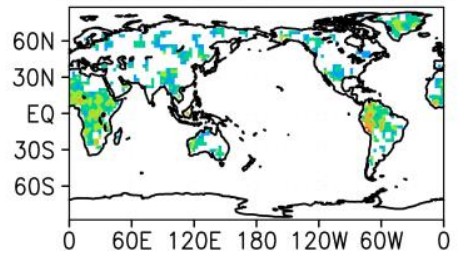

(f)

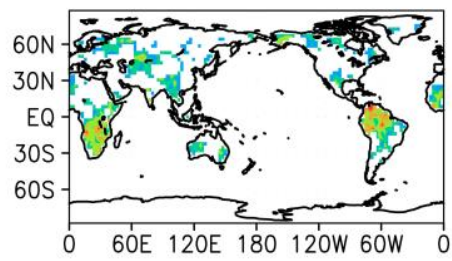

FIG. 17. As Fig. 16 but for $2 \mathrm{~m}$ surface temperatures (K). 

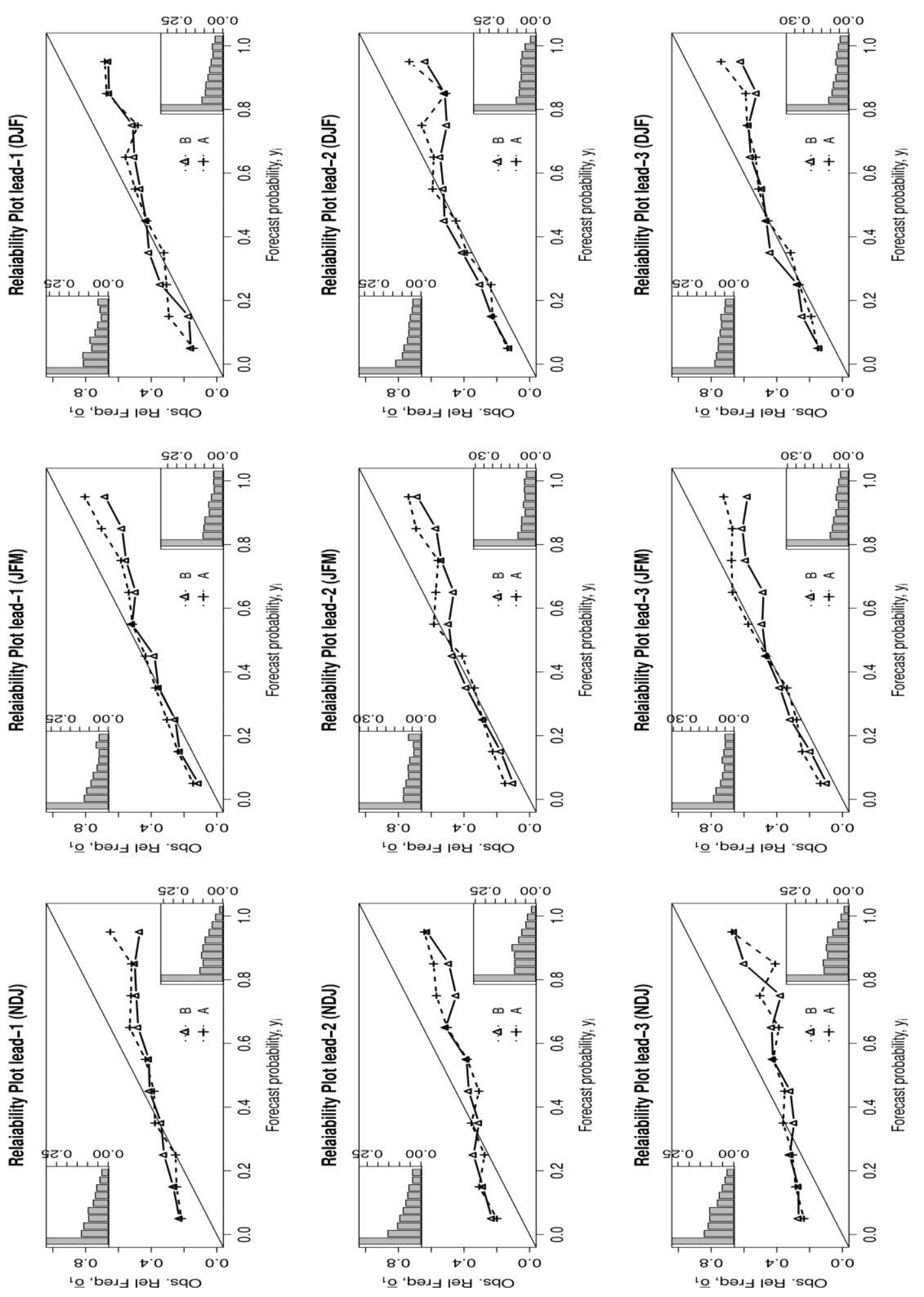
FIG. 18. Reliability diagrams of the OAGCM in predicting below- and above-normal surface air temperature conditions during the three rolling seasons centred around the austral summer season for the southern African region (South of the Equator). "B" and "A" in the legend denote cold and warm events respectively. The frequency of utilization the different probability bins for both below- and above-normal categories are also shown on the left top-upper and bottom-left corners of each diagram respectively.

Relaiability Plot lead-1 (DJF)

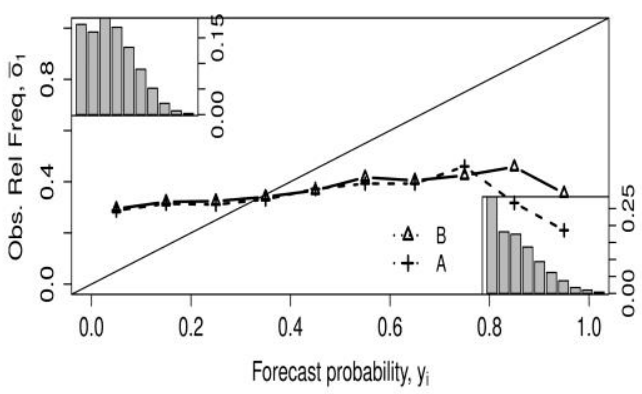

Relaiability Plot lead-2 (JFM)

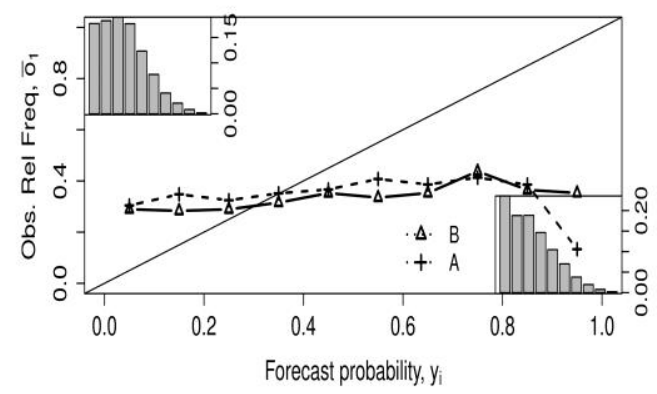

Relaiability Plot lead-3 (FMA)

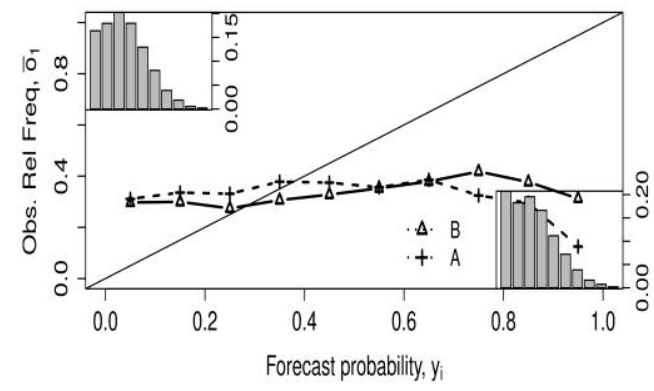

lead-1 (DJF)

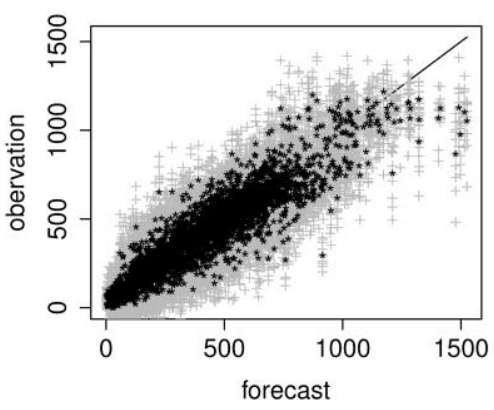

lead-2 (JFM)

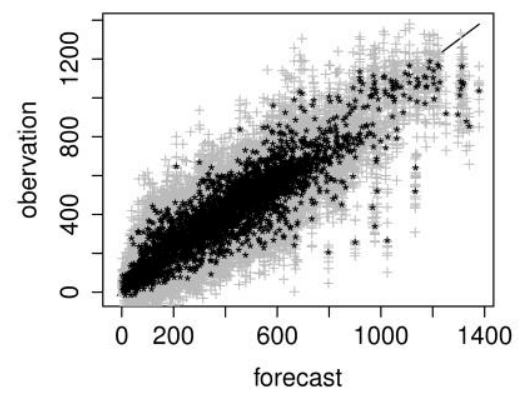

lead-3 (FMA)

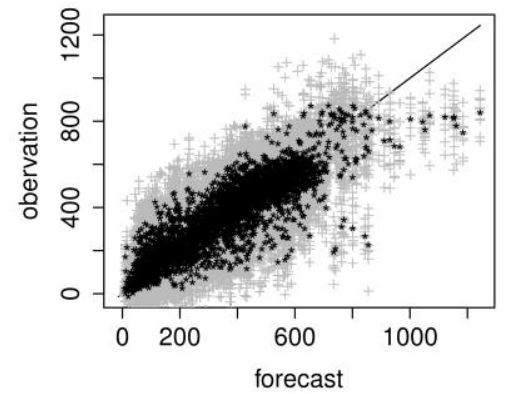


FIG. 19. reliability diagrams (right panel) as in Fig 18 but for November initialized hindcasts rainfall totals. The scatter diagrams (right panel) used the same inputs as in the reliability diagrams; the ensembles members are shown in grey $(+)$ and the ensemble mean is in black (*). No spatial average applied on the fields meaning that each grid point is contributed in each plot. 